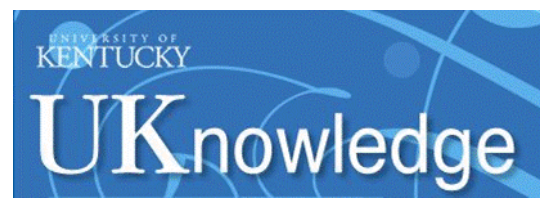

University of Kentucky

UKnowledge

$11-2014$

\title{
Pharmacokinetic and Pharmacodynamic Interactions between Antiepileptics and Antidepressants
}

\author{
Domenico Italiano \\ University of Messina, Italy \\ Edoardo Spina \\ University of Messina, Italy \\ Jose de Leon \\ University of Kentucky, jdeleon@uky.edu
}

Follow this and additional works at: https://uknowledge.uky.edu/psychiatry_facpub

Part of the Psychiatry and Psychology Commons

Right click to open a feedback form in a new tab to let us know how this document benefits you.

\section{Repository Citation}

Italiano, Domenico; Spina, Edoardo; and de Leon, Jose, "Pharmacokinetic and Pharmacodynamic Interactions between Antiepileptics and Antidepressants" (2014). Psychiatry Faculty Publications. 40. https://uknowledge.uky.edu/psychiatry_facpub/40

This Article is brought to you for free and open access by the Psychiatry at UKnowledge. It has been accepted for inclusion in Psychiatry Faculty Publications by an authorized administrator of UKnowledge. For more information, please contact UKnowledge@lsv.uky.edu. 


\section{Pharmacokinetic and Pharmacodynamic Interactions between Antiepileptics and Antidepressants}

Digital Object Identifier (DOI)

http://dx.doi.org/10.1517/17425255.2014.956081

Notes/Citation Information

Published in Expert Opinion on Drug Metabolism \& Toxicology, v. 10, Issue 11, p. 1457-1489.

(C) 2014 Taylor \& Francis Group

This is an Accepted Manuscript of an article published by Taylor \& Francis Group in Expert Opinion on Drug Metabolism \& Toxicology in Nov. 2014, available online: http://www.tandfonline.com/10.1517/ 17425255.2014 .956081 
This is an Accepted Manuscript of an article published by Taylor \& Francis Group in Expert Opinion on Drug Metabolism \& Toxicology in Nov. 2014, available online: http:// www.tandfonline.com/10.1517/17425255.2014.956081

\section{PHARMACOKINETIC AND PHARMACODYNAMIC INTERACTIONS BETWEEN ANTIEPILEPTICS AND ANTIDEPRESSANTS}

Domenico Italiano $^{1}$, Edoardo Spina ${ }^{1}$, Jose de Leon $^{2}$

${ }^{1}$ Department of Clinical and Experimental Medicine, University of Messina, and ${ }^{2}$ University of Kentucky Mental Health Research Center at Eastern State Hospital, Lexington, KY, and Psychiatry and Neurosciences Research Group (CTS-549), Institute of Neurosciences, University of Granada, Granada, Spain.

Corresponding author: Prof. Edoardo Spina, Department of Clinical and Experimental Medicine, University of Messina, Policlinico Universitario, Via Consolare Valeria, 98125 Messina, ITALY Telephone: +390902213647 Fax: +390902213300 E-mail: espina@unime.it

\section{Acknowledgments}

The authors acknowledge Lorraine Maw, M.A., and Margaret T. Boden, R.N., M.L.T. at the Mental Health Research Center at Eastern State Hospital, Lexington, KY, USA, who helped in editing the article.

\section{Declaration of interest}

No commercial organizations had any role in the writing of this paper for publication. Dr. Domenico Italiano has no conflicts of interest to declare. In the past few years, Dr. Spina has participated in speakers/advisory boards and lectures supported by AstraZeneca, Bristol-Myers, Eli Lilly \& Co, Janssen Pharmaceuticals, Lundbeck and Pfizer. Dr. de Leon personally develops his presentations for lecturing, has never lectured using any pharmaceutical or pharmacogenetic company presentations, and has never been a consultant for pharmacogenetic or pharmaceutical companies. In the past, Dr. de Leon received researcher-initiated grants from Eli Lilly (one ended in 2003 and the other, as co-investigator, ended in 2007); from Roche Molecular Systems, Inc. (ended 
in 2007); and, in a collaboration with Genomas, Inc., from the NIH Small Business Innovation Research program (ended in 2010). He has been on the advisory boards of Bristol-Myers Squibb (2003/04) and AstraZeneca (2003). Roche Molecular Systems supported one of his educational presentations, which was published in a peer-reviewed journal (2005). His lectures were supported once by Sandoz (1997), twice by Lundbeck (1999 and 1999), twice by Pfizer (2001 and 2001), three times by Eli Lilly (2003, 2006, and 2006), twice by Janssen (2000 and 2006), once by BristolMyers Squibb (2006), and seven times by Roche Molecular Systems, Inc. (once in 2005 and six times in 2006). 


\section{ABSTRACT}

Introduction: Antiepileptic-antidepressant combinations are frequently used by clinicians; their pharmacokinetic (PK) and pharmacodynamic (PD) drug interactions (DIs) have not been wellstudied but are frequently likely to be clinically relevant.

Areas covered: This article provides a comprehensive review of PK DIs between antiepileptics and antidepressants. In the absence of PD DI studies, PD information on pharmacological mechanisms and studies on efficacy and safety of individual drugs are reviewed.

Expert opinion: The clinical relevance of the inductive properties of carbamazepine, phenytoin, phenobarbital and primidone, and the inhibitory properties of valproic acid and some antidepressants are well understood; correction factors are provided if appropriate DI studies have been completed. More PK studies are needed for: i) antiepileptics with potent inductive effects for all recently approved antidepressants; ii) high doses of mild CYP3A4 inducers, such as clobazam, eslicarbazepine, oxcarbazepine, rufinamide and topiramate for reboxetine and vilazodone; iii) valproate as a possible inhibitor, mild inducer, or both a mild inducer and competitive inhibitor of some antidepressants; and iv) inhibitory effects of long-term fluoxetine use on clobazam, lacosamide, phenobarbital, primidone, carbamazepine, felbamate, tiagabine, and zonisamide. Possible synergistic or additive beneficial PD DIs in generalized anxiety disorder, chronic pain, migraine prophylaxis, weight control, and menopausal symptoms need study.

Keywords: antiepileptics; antidepressants; drug interactions; pharmacodynamics; pharmacokinetics.

\section{Highlights box}

-Pharmacokinetic (PK) and pharmacodynamic (PD) drug interactions (DIs) in antiepileptic and antidepressant combinations have not been well-studied but are frequently likely to be clinically relevant.

-More PK studies are needed for establishing dose-correction factors for i) antiepileptics with potent inductive effects for all recently approved antidepressants; ii) high doses of clobazam, eslicarbazepine, oxcarbazepine, rufinamide and topiramate, for reboxetine and vilazodone; iii) 
fluvoxamine as an inhibitor of clobazam, lacosamide, phenobarbital, and primidone; iv) fluoxetine as an inhibitor after several months of co-prescription for clobazam, lacosamide, phenobarbital, primidone, carbamazepine, felbamate, tiagabine, and zonisamide; v) high doses of sertraline as an inhibitor of valproate and lamotrigine; and vi) tricyclic antidepressants as inhibitors of lacosamide and clobazam.

-PD DI studies on antiepileptic-antidepressant combinations, information on the pharmacological mechanism and the efficacy and safety studies of individual drugs is provided to raise awareness of the potential for PD DIs.

-Possibly synergistic or additive beneficial PD DIs are: i) adding pregabalin to an antidepressant for generalized anxiety disorder; ii) combining carbamazepine, gabapentin, oxcarbazepine, or pregabalin with serotonin and noradrenaline reuptake inhibitors (SNRIs), or tricyclic antidepressants (TCAs) for chronic pain; iii) combining topiramate or valproic acid with amitriptyline or venlafaxine for migraine prophylaxis; iv) combining bupropion and zonisamide or topiramate for weight control; and v) combining gabapentin with SNRIs or selective serotonin reuptake inhibitors (SSRIs) for menopausal symptoms.

-Possibly synergistic or additive harmful PD DIs are some combinations of antiepileptics and antidepressants increasing the risk for sedation, weight gain, hyperlipidemia, nausea, urinary retention, hyponatremia, torsades de pointes, hepatic failure, hemorrhages, heat stroke and osteoporosis. 


\section{Introduction}

Antiepileptic drugs are traditionally divided into first- and second-generation compounds. In addition to the treatment of epilepsy, antiepileptics are extensively prescribed for the management of several non-epileptic neurological and psychiatric conditions $[1,2]$. In general, compared to the older drugs, newer antiepileptics have more advantageous pharmacokinetic characteristics, a wider therapeutic index, a more favorable tolerability and safety profile, and lower potential for drug interactions (DIs). For these reasons, despite the lack of definitive studies directly comparing the efficacy of first-generation and second-generation agents [3, 4], newer antiepileptics, particularly lamotrigine, levetiracetam and oxcarbazepine, have partially replaced older compounds in developed countries. Among first-generation agents, valproate is the only drug still prescribed as a first-line drug in males and non-fertile females. It is not a first choice in females of fertile age due to its teratogenicity potential.

Currently available antidepressants include older or classic agents, such as tricyclic antidepressants (TCAs) and monoamine oxidase inhibitors (MAOIs), and newer antidepressants, such as selective serotonin reuptake inhibitors (SSRIs), serotonin and noradrenaline reuptake inhibitors (SNRIs) and other antidepressants with varying mechanisms of action [5]. Over the past two decades, the newer antidepressants, particularly SSRIs, have become the drugs of choice for the management of depressive disorders, mainly because of their improved tolerability and safety profile as compared to TCAs. Antidepressant drugs are also widely used for the treatment of other psychiatric conditions including anxiety disorders, obsessive-compulsive disorder (OCD), eating disorders, and various forms of chronic pain such as diabetic neuropathic pain and fibromyalgia [5].

Antiepileptics and antidepressants are often prescribed together in patients with several heterogeneous conditions. Combined use is more likely for more recent compounds, which often exhibit a wider spectrum of indications. The incidence of depressive disorders in epileptic patients is estimated to be $30 \%-70 \%$ in their lifetime $[6,7]$. Therefore, due to this strict relationship between epilepsy and mood disorders, antidepressants are frequently co-prescribed in patients with epilepsy [8-11]. Valproate, carbamazepine and lamotrigine, when used as mood stabilizers, are frequently associated with antidepressants for the treatment of bipolar disorder [12-15]. Evidence for efficacy in bipolar disorder also exists for oxcarbazepine [16]. International guidelines for the treatment of neuropathic pain also include combined treatment with antidepressants and antiepileptics [17]. Pregabalin and gabapentin are commonly prescribed with a TCA or SNRI for this condition $[18,19]$. Pregabalin is approved for the treatment of generalized anxiety disorder in Europe and articles frequently recommend adding it to antidepressants for the treatment of generalized anxiety disorder with comorbid mood depression [20, 21]. Moreover, antidepressants 
may be co-prescribed with topiramate and valproate for migraine prophylaxis, or exclusively to treat migraine comorbid with depression $[22,23]$.

Considering the frequent co-prescription of antiepileptics and antidepressants, it is essential for clinicians to be aware of the potential DIs between these compounds. The consequences of a DI can be either beneficial, if the interaction results in increased therapeutic efficacy or reduced risk of adverse drug reactions (ADRs), or harmful, if it leads to decreased efficacy or enhanced toxicity of one or more of the administered medications. Based on their mechanisms, DIs can be classified into two main categories, pharmacokinetic (PK) and pharmacodynamic (PD).

In recent years, a number of comprehensive reviews of clinically relevant pharmacokinetic DIs involving antiepileptics [24-28] or antidepressants [29-33] or combinations [34, 35] have been published. The aim of the present article is to provide an updated review of clinically significant DIs between antiepileptics and antidepressants including not only PK DIs but also PD DIs.

Articles for this review were obtained from a PubMed search with no time limit. Searches were performed for each of the antiepileptics and antidepressants. Only articles published in peerreviewed journals were included, while meeting abstracts were excluded. Information was also obtained from the individual product inserts of each antiepileptic or antidepressant. Additional DI information was also obtained from citations of the articles that were retrieved during our search, and these were also included in our review. This search was beyond the articles previously found and listed in the authors' published literature reviews and DI studies.

\section{Basic mechanisms of DIs between antiepileptics and antidepressants}

\subsection{PK DIs}

PK DIs consist of changes in the absorption, distribution, metabolism or excretion of a drug and/or its metabolite(s) after the addition of another drug. These DIs are associated with a modification in plasma concentration of either the drug or its metabolite(s) and usually are easily verified by therapeutic drug monitoring (TDM). PK parameters of antiepileptics and antidepressants are summarized in Tables 1 and 2, respectively.

To our knowledge, no clinically relevant DI has been described so far during at the absorption phase or protein binding [36-37] between compounds of these two drug classes.

The vast majority of clinically important PK DIs between antiepileptics and antidepressants occur at a metabolic level and usually involve the hepatic cytochrome P450 (CYP) system and, to a lesser extent, the uridine diphosphate glucuronosyltransferase (UGT) system [38]. Knowledge of the properties of the major drug-metabolizing enzymes with identification of substrates, inhibitors, 
and inducers of different CYP isoforms can provide some clues to clinicians as to the likelihood of a clinically relevant DI occurring [38]. In principle, concomitant treatment with drugs metabolized by the same enzyme or coadministration of a drug with another medication acting as an inhibitor or inducer involves a DI risk. A number of drug-related (i.e., potency and concentration/dose of the inhibitor/inducer, therapeutic index of the substrate, extent of metabolism of the substrate through the affected enzyme, presence of active metabolites), patient-related (i.e., age, genetic predisposition) and environmental factors (i.e., smoking) will then influence the potential occurrence, magnitude, and clinical significance of a metabolic DI [37]. As shown in Tables 1 and 2, most antiepileptics (with the exception of gabapentin, pregabalin and vigabatrin) and antidepressants are extensively metabolized via CYPs or UGTs. As many compounds of these two therapeutic classes share common metabolic pathways, potential DIs may be anticipated Furthermore, antiepileptics may be involved in metabolically-based DIs because they act as inhibitors or inducers of various drug-metabolizing systems. Among first-generation agents, carbamazepine, phenytoin, phenobarbital and primidone (enzyme-inducing antiepileptics) induce the activity of CYP1A2, CYP2C9, CYP2C19 and CYP3A4, as well as UGTs and epoxide hydrolase. Valproic acid is a broad-spectrum inhibitor of various drug-metabolizing enzymes including CYP2C9 and UGTs and, recently, some inductive effects have been demonstrated. The newer antiepileptics are associated with limited enzyme-inducing potential compared with oldergeneration compounds. However, clobazam, eslicarbazepine, felbamate, oxcarbazepine (at dosages $\geq 1200 \mathrm{mg} /$ day), rufinamide and topiramate (at dosages $\geq 400 \mathrm{mg} /$ day) can induce the activity of CYP3A4 and, possibly, some UGTs (Table 1). Some of the newer antiepileptics may at times act as enzyme inhibitors. Eslicarbazepine, felbamate, oxcarbazepine and topiramate are weak inhibitors of CYP2C19, while stiripentol is a potent inhibitor of CYP1A2, CYP2C19, CYP2D6 and CYP3A4. Concerning older antidepressants, in vitro evidence indicates that TCAs may inhibit the activity of CYP2C19 (moderately) and CYP2D6 (weakly) [39]. On the other hand, some newer antidepressant agents including fluoxetine, fluvoxamine, paroxetine, duloxetine and bupropion, act as potent or moderate inhibitors of various CYPs and may therefore impair the elimination of antiepileptic agents metabolized via these isoforms [29, 31, 32].

PK DIs between antiepileptics and antidepressants may theoretically occur during the excretion phase. While some newer antiepileptics such as gabapentin, pregabalin, vigabatrin, levetiracetam and topiramate are eliminated predominantly through the kidneys, antidepressants are predominantly eliminated by drug metabolism. Only desvenlafaxine and milnacipran are largely excreted unchanged in the urine. So far, there are no reports of clinically significant DIs between antiepileptics and antidepressants at the renal excretion level. 
PK DIs between antiepileptics and antidepressants may also involve drug transporters, in particular, P-glycoprotein (P-gp), which plays an important role in the absorption, distribution and excretion of a wide variety of therapeutic agents [40]. As some antiepileptics and antidepressants may be substrates, inducers or inhibitors of P-gp [41-43], it can be speculated that some DIs between antiepileptics and antidepressants previously believed to be CYP-mediated are now also considered to be due to the modulation of multidrug-transporters.

\subsubsection{PKs of inducer antiepileptics and endogenous substrates}

Some ADRs from potent inducers may be explained by the induction of endogenous compounds [44-53], but they may manifest only after the organism has not been able to compensate for these disturbances in homeostasis present for months or years (Figure 1),

\subsection{PD DIs}

The importance of PD mechanisms of antiepileptics and antidepressants are often underestimated in most articles reviewing DIs. This subsection briefly lists the PD properties of antiepileptics and antidepressants; they are described more comprehensively in Figures 2 to 5 and their detailed footnotes. At the end of this section, a subsection comments on the types of PD DIs.

\subsubsection{PDs of antiepileptics}

Figure 2 summarizes the mechanism of action of antiepileptics in epilepsy, bipolar disorder, anxiety, pain, migraine prophylaxis, weight loss and other indications. Figure 3 summarizes the mechanism of action of antiepileptics associated with major safety issues.

\subsubsection{PDs of antidepressants}

Figure 4 summarizes antidepressant mechanisms of action in several disorders including depression, OCD, anxiety, pain, weight loss and other indications. Textbooks usually report that the majority of antidepressants act by inhibiting reuptake transporters but the chronology of reuptake inhibition does not match the chronology of antidepressant response [5, 54]. Only four TCAs, amitriptyline, clomipramine, imipramine, and nortriptyline, are described in the figures and tables. Figure 4 lists SSRIs, SNRIs and other newer antidepressants with different mechanisms. Nefazodone and MAOIs are not included in this article. Figure 5 summarizes antidepressant mechanisms of action associated with major safety issues.

\subsubsection{Pharmacological knowledge and PD DIs}


PD DIs result in a modification of the pharmacological action of a drug by a direct effect on its site of action or, alternatively, by interfering with another physiological mechanism related to drug action. Therefore, they occur without any change in the plasma concentration and are more difficult to recognize and quantify than PK DIs. PD DIs can be classified as additive (i.e., equal to the sum of the effects of the individual drugs), synergistic (i.e., the combined effects are greater than expected from the sum of individual effects) or antagonistic (i.e., the combined effects are less than additive) [37]. They can involve beneficial effects (increased efficacy and/or safety) or harmful effects (decreased efficacy and/or safety).

\section{Specific DIs between antiepileptics and antidepressants}

\subsection{PK DIs}

\subsubsection{Effect of antiepileptics on the PKs of antidepressants}

\section{First-generation antiepileptics}

The first-generation antiepileptics, namely carbamazepine, phenytoin, phenobarbital and primidone, may induce antidepressant metabolism, as they are powerful inducers of several drugmetabolizing enzymes including CYPs, specifically CYP1A2, CYP2A6, CYP2B6, CYP2C9, CYP2C19, CYP3A4, as well as UGTs such as UGT1A1, UGT2B7, and UGT2B15.

Early PK studies [34] have repeatedly documented that, concomitant treatment with enzyme-inducing antiepileptics was associated with a decrease in plasma concentrations of various TCAs. Because the demethylation of TCAs is catalyzed by multiple isozymes, including CYP2C19 and, to a lesser extent, CYP1A2, CYP2C9 and CYP3A4 [55, 56], induction of these isoforms is the most likely explanation for the observed PK changes. Another major enzyme contributing to the metabolism of TCAs, in particular to the hydroxylation reactions, CYP2D6 is generally regarded to be non-inducible, even though in two formal kinetic studies the 2-hydroxylation of desipramine, a reaction primarily catalyzed by CYP2D6, was found to be accelerated by carbamazepine and phenobarbital $[57,58]$. In a subsequent investigation in 13 patients with major depression stabilized with imipramine, the addition of carbamazepine, at a dose of $400 \mathrm{mg} /$ day for two weeks, caused a significant decrease in mean steady-state concentrations of imipramine and its active metabolite desipramine, by $42 \%$ and $41 \%$, respectively, while the free concentrations of both imipramine and desipramine increased [59]. The authors speculated that carbamazepine may affect not only the metabolism of imipramine and desipramine, but also their protein binding. Irrespective of the mechanism of the interaction, the decrease in plasma concentrations of TCAs is likely to have clinical implications and individual patients on long-term treatment with enzyme-inducing antiepileptics may require higher doses to achieve an optimal therapeutic response. 
Regarding SSRIs, phenobarbital, phenytoin and carbamazepine have been reported to decrease by about $25 \%$ the plasma levels of paroxetine, probably as a result of accelerated metabolism $[60,61]$. Administration of carbamazepine, an inducer of CYP3A4, was associated with a marked decrease in plasma sertraline concentrations in two patients, resulting in lack of antidepressant efficacy [62]. In an open pilot study involving 6 patients with major depression stabilized on citalopram (40-60 mg/day), a 4-week augmentation therapy with relatively low doses of carbamazepine (200-400 mg/day) caused a significant decrease in plasma concentrations of Scitalopram and R-citalopram by 27 and 31\% (both, p $<0.05$ ), respectively [63]. This effect was attributed to nonstereoselective induction of CYP3A4-mediated N-demethylation of citalopram by carbamazepine.

Carbamazepine, a CYP3A4 inducer, $200 \mathrm{mg}$ twice a day for 32 days, caused a $20 \%$ decrease in milnacipran plasma concentrations [64]. Two PK investigations evaluated the reciprocal interaction between the new antidepressant mirtazapine (30 mg/ day) and carbamazepine (400 $\mathrm{mg}$ /day) or phenytoin (200 mg/day) in healthy subjects under steady-state conditions $[65,66] . \mathrm{In}$ the first study, coadministration with carbamazepine in 24 healthy volunteers caused a mean reduction by $39 \%$ in the peak plasma concentration $\left(\mathrm{C}_{\max }\right)$ of mirtazapine and by $61 \%$ in the area under the plasma concentration-time curve (AUC) [65]. Similarly, addition of phenytoin to 17 healthy male subjects resulted in a mean decrease of the $\mathrm{C}_{\max }$ of mirtazapine by $33 \%$ and in its AUC by a $47 \%$ decrease [66]. The reduction in mirtazapine concentrations is presumably due to induction of CYP3A4-mediated metabolism of mirtazapine by carbamazepine and phenytoin. Carbamazepine may also induce the biotransformation of bupropion, a new antidepressant which inhibits the reuptake of noradrenaline and dopamine. In a study involving 12 patients with mood disorders given a single $150 \mathrm{mg}$ dose of bupropion, addition of carbamazepine, at a mean dose of $942 \mathrm{mg} /$ day, was found to decrease the $\mathrm{C}_{\max }$ of bupropion by $87 \%(\mathrm{p}<0.001)$ and its AUC by $90 \%$ $(p<0.001)$ [67]. Carbamazepine increased the AUC of its metabolite hydroxybupropion by $50 \%$ $(\mathrm{p}<0.05)$. As hydroxybupropion may contribute to therapeutic or adverse effects, the clinical significance of this DI has not yet been established. A case report described two patients with low serum concentrations of reboxetine in relation to the dose during carbamazepine or phenobarbital treatment probably mediated by CYP3A4 induction [68].

Valproate has traditionally been considered a broad-spectrum metabolic enzyme inhibitor. It inhibits CYP2C9 competitively, CYP2C19 and CYP3A4 weakly and has no effects on CYP1A2, CYP2D6, and CYP2E1. It inhibits UGT enzymes (UGT1A4 and UGT2B7) [37]. However, a human hepatocyte study surprisingly demonstrated that valproate may induce some enzymes 
(CYP3A4 and P-gp gene expression) [69]. Moreover, recent clinical studies indicate that valproate may behave as a mild inducer in some circumstances [70].

Two studies have reported a $50 \%$ to $60 \%$ elevation in plasma amitriptyline and nortriptyline concentrations in depressed patients comedicated with valproate $[71,72]$. In a PK investigation in 15 healthy subjects, the mean $\mathrm{AUC}$ and $\mathrm{C}_{\max }$ for the sum of amitriptyline and nortriptyline increased by $42 \%$ and $19 \%$, respectively, after the addition of valproate [73]. Moreover, an elevation of serum nortriptyline or clomipramine concentrations in association with valproate comedication was observed in case reports [74-75]. Severe ADRs associated with a considerable increase in serum levels of TCAs during valproate treatment has been described in case reports [7678]. Unterecker et al. [79] have recently evaluated the influence of valproic acid on amitriptyline and nortriptyline serum concentrations by a retrospective analysis of TDM data under naturalistic conditions. When comparing 33 patients receiving amitriptyline in combination with valproic acid versus 33 patients on amitriptyline monotherapy, dose-corrected serum concentrations of amitriptyline, nortriptyline and their sum were significantly higher $(\mathrm{p}<0.001)$, by $67 \%, 128 \%$ and 94\%, respectively, in patients on comedication. The interaction between valproate and TCAs may be explained by an inhibitory effect of valproate on CYP2C9 and, possibly, CYP2C19 and CYP3A4, which play a role in the biotransformation of TCAs $[55,56]$. In a subsequent study based on the same TDM database, the same authors [80] examined the potential DI between valproic acid and doxepin and venlafaxine, an SNRI agent. The mean dose-corrected serum concentrations of doxepin plus $\mathrm{N}$-doxepin in 16 patients who received valproic acid comedications were significantly higher (by $124 \%, \mathrm{p}<0.01$ ) than in the matched controls of patients on doxepin alone. The mean dose-corrected serum concentrations of venlafaxine plus O-desmethylvenlafaxine in 41 patients receiving valproic acid comedications did not differ significantly from those of the matched controls. However, the dose-corrected serum concentrations of the active metabolite Odesmethylvenlafaxine were significantly higher (by $27 \%$, p <0.02) in patients treated with the combination of valproic acid with venlafaxine. The increase in serum concentrations of doxepin plus N-doxepin is attributed to the inhibitory effect of valproate on CYP2C9 [81]. To explain the elevation of serum concentrations of O-desmethylvenlafaxine, the authors speculate that the inhibition of the CYP2C9-mediated N-demethylation of venlafaxine by valproate may lead to a stronger O-demethylation and, as a consequence, to higher serum levels of O-desmethylvenlafaxine [82]. Unlike carbamazepine, valproic acid did not affect the metabolism of bupropion in patients with depression [67].

\section{Second-generation antiepileptics}


Compared with first-generation agents, second-generation antiepileptics have a lower propensity to cause PK DIs. To our knowledge, no systematic study has documented the effect of newer antiepileptics on the disposition of antidepressants. Baird [83] described a case of a possible clomipramine induction by oxcarbazepine.

\subsubsection{Effect of antidepressants on the PKs of antiepileptics}

\section{Older antidepressants}

While some antiepileptics can profoundly affect TCA plasma concentration, there is little evidence that TCAs can influence the pharmacokinetics of anticonvulsants. One study showed that nortriptyline coadministration produced a small increase in phenytoin levels [34], while in another report plasma phenytoin concentration was found to increase in two patients during treatment with imipramine and to return to baseline after its discontinuation [34].

\section{Newer antidepressants}

Fluoxetine and its metabolite norfluoxetine are potent inhibitors of CYP2D6 and moderate inhibitors of CYP2C9, while they mildly to moderately affect the activity of CYP2C19 and CYP3A4 [31, 84]. Case reports indicated that concurrent use of fluoxetine and phenytoin can result in significantly increased phenytoin serum levels leading to toxicity [85-87]. This DI has been attributed to the moderate inhibitory effect of fluoxetine on the CYP2C9-mediated biotransformation of phenytoin [88]. Fluoxetine may also impair the elimination of carbamazepine, as documented by case reports after the addition of fluoxetine $[89,90]$. Conversely, no changes in steady-state carbamazepine levels were observed in eight epileptic patients on a chronic treatment with carbamazepine (800-1600 mg/day) after a 3-week coadministration with fluoxetine, 20 $\mathrm{mg}$ /day, suggesting that inhibition of CYP3A4-mediated carbamazepine metabolism might occur only at higher fluoxetine doses [91] or require more than 3 weeks to manifest, due to the long halflife of norfluoxetine. Early case reports had documented that the addition of fluoxetine to an ongoing treatment with valproic acid may increase steady-state plasma concentrations of valproic acid, along with showing signs of toxicity [92-94]. The most plausible explanation for the raised valproic acid levels is inhibition of CYP2C9 by fluoxetine. In a large routine TDM program for lamotrigine, dose-normalized serum concentrations of lamotrigine were significantly lower (by $39 \%$ ) in 15 patients taking fluoxetine than in the reference group of 224 subjects on lamotrigine alone [95]. As fluoxetine is not a known enzyme inducer, but is a potent inhibitor of CYP enzymes, the authors speculate that fluoxetine or its metabolite norfluoxetine may induce the UGT enzymes involved in the glucuronidation of lamotrigine. 
Paroxetine is a potent inhibitor of CYP2D6, while it only minimally affects other CYPs [31, 84]. In a single-blind, placebo-controlled, cross-over study of 20 patients with epilepsy, stabilized on phenytoin, carbamazepine or valproic acid, addition of paroxetine, $10-30 \mathrm{mg} /$ day for 16 days, caused no significant changes in plasma concentrations of these antiepileptic drugs [61].

Fluvoxamine influences the activity of various CYP isoenzymes; it is a potent inhibitor of CYP1A2 and CYP2C19 and a moderate inhibitor of CYP2C9 and CYP3A4, while it affects CYP2D6 activity only slightly [31,84]. Being an inhibitor of different CYP isoforms, fluvoxamine may impair the elimination of various antiepileptics. There is conflicting evidence for a metabolic DI between fluvoxamine and carbamazepine. Although case reports have documented that fluvoxamine increased carbamazepine levels with associated symptoms of carbamazepine toxicity $[96,97]$, one study of seven epileptic patients stabilized on carbamazepine (800-1600 mg/day) found no such increase in carbamazepine levels after three weeks of coadministration with fluvoxamine, $100 \mathrm{mg} /$ day [91]. A case report documented a 3-fold increase in serum concentrations of phenytoin after administration of fluvoxamine [98]. This pharmacokinetic change was explained as a result of inhibition of both CYP2C9 and CYP2C19 by fluvoxamine.

Sertraline is a mild to moderate in vitro inhibitor of CYP2D6 and a weak inhibitor of the other CYP isoenzymes [31, 84]. Two RCTs, using double-blinding and placebo in healthy volunteers, have documented that sertraline, at a dose of $200 \mathrm{mg}$ /day for 17 days, did not affect the pharmacokinetics of carbamazepine $(400 \mathrm{mg} /$ day for 32 days; $\mathrm{n}=14)$ and phenytoin $(300 \mathrm{mg} / \mathrm{day}$ for 24 days; $\mathrm{n}=30$ ), substrates for CYP3A4 and CYP2C9, respectively [99, 100]. On the other hand, in a patient with bipolar depression treated with valproate, the addition of sertraline (100 $\mathrm{mg}$ /day) resulted in a 3-fold elevation in serum valproic acid concentration associated with signs of valproate intoxication [101]. A clinically relevant PK DI may also occur between sertraline and lamotrigine, a new antiepileptic which is predominantly metabolized by glucuronide conjugation. A two-fold increase in plasma lamotrigine concentration associated with symptoms of toxicity was observed in two epileptic patients 6 weeks after the addition of a low dose of sertraline, $25 \mathrm{mg} / \mathrm{day}$ [102]. In a recent study aimed at evaluating the potential DI between sertraline and lamotrigine, dose-corrected concentrations of lamotrigine were slightly, but not significantly, higher (by 18\%) in 7 patients treated with both drugs in combination than in the 44 patients receiving only lamotrigine [103].

Citalopram and its active S-enantiomer, escitalopram, are weak in vitro inhibitors of CYP2D6 and are negligible inhibitors of CYP1A2, CYP2C9, CYP2C19 and CYP3A4 [104, 105]. Due to their minimal effect on drug-metabolizing enzymes, citalopram and escitalopram are not expected to cause clinically relevant DIs with antiepileptic drugs. In an open-label investigation in 
12 healthy volunteers, the addition of citalopram, $40 \mathrm{mg} /$ day for 14 days, to carbamazepine, administered at the dose of $400 \mathrm{mg} /$ day for 35 days, did not alter the steady-state PK parameters of carbamazepine and its active epoxide metabolite [106].

According to two investigations in healthy subjects, mirtazapine $(30 \mathrm{mg} /$ day) had no effect on PK parameters of both carbamazepine and phenytoin $[65,66]$.

Anecdotal evidence indicates that bupropion may inhibit the metabolism of phenytoin and valproate [107]. On the other hand, in a randomized, open-label, two-way crossover study in 12 healthy subjects, PK parameters of a single oral dose of $100 \mathrm{mg}$ lamotrigine were not affected by steady-state bupropion, $150 \mathrm{mg}$ twice/day [108].

\subsection{PD DIs}

\subsubsection{PD DIs that increase efficacy}

Pharmacodynamic drug interactions are rarely systematically studied, but there is some limited literature supporting the theory that the combination of antiepileptic-antidepressants may have additive and/or synergistic effects for treatment-resistant depression, anxiety, pain, migraine prophylaxis and weight loss.

There are a few studies on the possible role of some antiepileptics for potentiating antidepressants in major depressive disorder. They provide suggestive evidence of the beneficial effects of adjunctive carbamazepine, lamotrigine, and valproate, particularly in patients taking antidepressants for recurring major depressive disorder with prominent irritability or agitation [109] but augmentation strategies, including lithium and antipsychotics, are usually preferred [110].

Pregabalin has been approved for generalized anxiety disorder in Europe. A RCT indicated that adjunctive therapy with pregabalin in patients with a partial response to antidepressants in generalized anxiety disorder was more effective than placebo [20] and this augmentation strategy is recommended by a recent guideline [111]

Different antiepileptics and antidepressants are used as alternatives to analgesic opioids for the treatment of chronic pain including fibromyalgia, painful diabetic neuropathy, postherpetic neuralgia, neuropathic pain and painful neuropathy [112; Figures 3 and 5]. Clinicians and some of the pain guidelines [112] recommend combinations of antiepileptics and antidepressants, as they may work using different analgesic mechanisms. The number of RCTs demonstrating greater efficacy of the antiepileptic-antidepressant combinations than the individual drugs is limited and includes the combination of nortriptyline and gabapentin for neuropathic pain [113], and low-dose pregabalin and low-dose antidepressants as adjunctive to opioids for intractable painful bone metastasis [114]. 
For migraine prophylaxis, meta-analyses support the efficacy of approved drugs including topiramate and valproate $[115,116]$ and off-label TCAs, particularly amitriptyline $[115,117]$. There is limited evidence for the use of some other antidepressants, including venlafaxine [115], but clomipramine is considered ineffective in migraine prophylaxis [23]. Guidelines do not comment on drug combinations for migraine prophylaxis [23], but clinicians use them. A recent RCT obtained a response of $37 \%$ in monotherapy versus $78 \%$ in the combination of topiramate and nortriptyline [118].

Both bupropion and zonisamide have been associated with weight loss but probably have different mechanisms of action (Figures 3 and 5). An article reviewing RCTs using this combination suggested that the combination may have additive effects [119], but the RCTs have not yet been published.

Some articles implied the possibility of additive- and/or synergistic-type PD DIs between antiepileptics and antidepressants for two unapproved indications: menopausal vasomotor symptoms (Figures 2 and 4) and treatment-resistant OCD.

Hormonal replacement has been the treatment of menopausal hot flashes but there is increased concern about its risk, leading to an increased use of non-hormonal therapies for vasomotor symptoms (hot flashes and night sweats) in patients with natural or iatrogenicallyinduced menopause. Gabapentin and some antidepressants, SSRIs and SNRIs, have been studied and appear to be better than placebo for menopausal symptoms (Figure 2 and 4). No RCT with combined treatment has been published and a recent cross-over RCT [120] does not address the combined effects.

There are few RCTs with antiepileptics in OCD, but one [121] suggests that lamotrigine may potentiate the effects of serotonergic reuptake inhibitors in treatment-resistant OCD, possibly due to its glutamatergic effects. A recent guideline recommended SSRI augmentation with lamotrigine or topiramate as one of the options after initial SSRI non-response in OCD [111].

\subsubsection{PD DIs that decrease efficacy}

The literature provides some support for an antagonistic PD DI for antidepressants in bipolar disorder maintenance. There is very limited RCT data on maintenance treatment after bipolar depression [122], but there is general agreement that some antidepressants may increase the switch to mania, whereas bupropion and SSRIs may have fewer risks than TCAs and SNRIs [123]. A meta-analysis suggested that mood stabilizers may not prevent the switch to mania induced by antidepressants, but too few studies have been conducted to establish certainty [124]. Future studies 
will need to verify whether or not antidepressants decrease the mood-stabilizing properties of mood stabilizers by increasing mania-switching [125].

Figure 3 indicates depression is considered a common ADR to phenobarbital, primidone, topiramate and vigabatrin. These antiepileptics should be used very cautiously in patients with a history of depression. Other antiepileptics associated with depression, but less frequently, are felbamate, levetiracetam, tiagabine and zonisamide. Although there are no studies supporting this, it is pharmacologically reasonable to think that any of these antiepileptics can decrease or eliminate the antidepressant effects in patients taking antidepressants.

Figure 5 indicates that bupropion and TCAs can decrease the seizure threshold and, as a matter of fact, they have been associated with seizures in patients without history of epilepsy [126]. A meta-analysis of RCTs suggested that other newer antidepressants, which were combined in the same group for statistical analysis, appeared to have less seizure risk than placebo [127]. Fluoxetine animal studies suggest that it may have anti-seizure activity and can potentiate valproate anticonvulsant effects [128]. In summary, bupropion and TCAs (maprotiline may be the worst) should not be prescribed to epileptic patients with poor seizure control, since they can decrease the efficacy of antiepileptics.

\subsubsection{PD DIs that increase safety}

Topiramate and zonisamide can decrease weight when taken with antidepressants associated with weight gain (amitriptyline, mirtazapine, paroxetine) but there are no published studies. Bupropion can decrease weight when taken with antiepileptics associated with weight gain but, as previously described, it had the potential of decreasing the seizure threshold.

Antiepileptics in some peculiar circumstances may decrease the risk of arrhythmias associated with antidepressants. Phenytoin may have beneficial effects on TCA overdoses [129]. Rufinamide is an unusual drug in the sense that it has been definitively associated with dosedependent reduction of QT interval [130] and has the potential to decrease QTc prolongations in patients with SSRI-induced QT prolongations.

\subsubsection{PD DIs that decrease safety}

Non-studied PD DIs possibly associated with specific antidepressant compounds in combination with antiepileptics may include increased risk for sedation, weight gain and metabolicassociated symptoms, nausea and urinary symptoms.

Sedation is a very common ADR for antiepileptics (except for felbamate, lacosamide, lamotrigine and tiagabine, which may have a frequency $<10 \%$ in RCTs). Antidepressants with 
clinically relevant antagonism of histamine $1\left(\mathrm{H}_{1}\right)$ receptors including TCAs, trazodone and mirtazapine are likely to increase the risk of sedation in patients taking antiepileptics; therefore, prescribers may want to consider other antidepressants in patients taking antiepileptics.

The compounds associated with weight gain include among antiepileptics, carbamazepine, gabapentin, pregabalin, retigabine, and valproate, and among antidepressants [49], some TCAs, mirtazapine and paroxetine [131]. Therefore, the combination of any of these antiepileptics associated with weight gain may have additive effects. The only antidepressant clearly associated with hyperlipidemias is mirtazapine [132]. It should be cautiously added to potent inducer antiepileptics that have been associated with hyperlipidemias (carbamazepine, phenobarbital, phenytoin, and primidone; Figure 1).

Nausea and vomiting are common ADRs in almost all antiepileptics $[133,134]$ and are also common for SSRIs and SNRIs [135]. Although there are no published articles addressing this issue, it is not surprising that there are increased risks for nausea if antiepileptics are combined with SSRIs or SNRIs. TCAs [136] and mirtazapine [137] have occasionally been used as antiemetics.

Retigabine can cause urinary retention due to its interference with bladder voltagedependent potassium channels [138]. It should be very cautiously combined with antidepressants associated with urinary retention, including more potent antimuscarinic antidepressants (most TCAs, mirtazapine and paroxetine), reboxetine and SNRIs (Figure 4).

Less common PD DIs possibly associated with combinations of antiepileptics and antidepressants may include increased risk for lethal ADRs including hyponatremia, arrhythmias, hepatotoxicity, hemorrhages and heat stroke.

Many antidepressants [139] and two antiepileptics [140], oxcarbazepine and carbamazepine, appear to be consistently associated with hyponatremia, probably mediated by increasing antidiuretic hormone $(\mathrm{ADH})$ release and/or action. Clinical manifestations are relatively uncommon and are more frequent in elderly females [139]. Recent larger hyponatremia studies [141] did not explore the possibility that combinations of an antidepressant with one of these antiepileptics may be more prone to cause symptomatic hyponatremia that the individual drugs.

Lethal arrhythmias are very complicated to study since these deaths are relatively rare and are not easily identified in autopsies. Several syndromes are associated with sudden cardiac death. One of them is Brugada syndrome (see footnote 7 of Figure 3), which has been linked with newer antidepressants (Figure 5) and some antiepileptics (Figure 3) [142]. Obviously, the listed antiepileptics and antidepressants should be avoided in these patients and never combined.

Several antidepressants have been associated with torsades de pointes including citalopram, fluoxetine and sertraline (Figure 5) [143, 144]. They should not be combined with felbamate, which 
has also been associated with torsades de pointes, or with retigabine, which has been associated with QTc prolongations (Figure 3).

Agomelatine has been definitively associated with liver enzyme elevations. Most cases (90\%) recover after agomelatine discontinuation but severe forms can also occur [145]. Agomelatine should be very carefully prescribed when started in any patients using antiepileptics with greater risk of hepatotoxicity including carbamazepine, felbamate, phenytoin and valproate. In their recent review, Voican et al. [146] stated that, besides agomelatine, bupropion, duloxetine, TCAs and trazodone are the most frequent antidepressants that, on rare occasions, can cause lifethreatening hepatotoxicity. They suggest that these antidepressants should not be administered in those with prior liver problems. Therefore, we propose that bupropion, duloxetine, TCAs and trazodone should not be used in those with prior history of liver injury secondary to antiepileptics, or with current liver enzyme elevations during antiepileptic treatment.

Figure 5 indicates that epidemiological studies definitively establish SSRIs as producing a small increased risk for abnormal bleeding by depleting platelets from serotonin, particularly when other risk factors are present, such as some drugs or surgery [147]. Valproate causes a common dose-related thrombocytopenia and on rare occasions interferes with the coagulation system [148; Figure 3] and may increase the risk of SSRI-induced bleeding, but this DI has not been studied.

Topiramate and zonisamide are inhibitors of carbonic anhydrase, decreasing the ability to produce sweat. Antimuscarinic drugs such as TCAs and mirtazapine can also cause hypohidrosis [149]. Combinations of topiramate or zonisamide with most potent antimuscarinic antidepressants should be avoided during hot summers, particularly in the elderly, or in patients exposed to strenuous exercise.

Suicide and osteoporosis are two possible ADRs that have been associated with antiepileptics and antidepressants, but the connections are not definitively established due to the difficulty of studying them. If these associations are not spurious, the combinations of these drugs may increase the risk.

After meta-analyses, the US Food and Drug Administration (FDA) issued separate warnings of suicidality with antidepressants and antiepileptics. The risk of suicidality on antidepressants decreased and the benefits increased with age. There was a significant twofold risk of suicidality among children and adolescents randomized to antidepressants; whereas there was a statistically significant protective effect of antidepressants among those 65 and older [150]. Risk of suicidality, mainly suicidal ideation, was significantly elevated among subjects randomized to receive an antiepileptic, compared with placebo [151]. As these warnings come from studies in which it is not easy to eliminate confounders, including the presence of psychiatric disorders, the warnings are 
considered controversial by many clinicians. The literature does not comment on the possibility of the increased risk of suicide in combining antiepileptics and antidepressants. Leon et al., [152] using a sophisticated statistical approach to analyze observational studies, concluded that the risk of suicide attempts or suicides was significantly reduced when the participants received antidepressants. However, there was neither significant risk nor protection from suicidality among participants receiving antiepileptics.

Strong inducer antiepileptics are definitively associated with osteoporosis (Figure 1) and epidemiological studies [153] are starting to suggest that SSRIs may also be associated with increased risk for osteoporosis (Figure 4). Although it has not been studied, they may potentiate each other's effects on osteoporosis.

\section{Conclusion}

This section and Table 4 provide a summary of the most important practical DI information for clinicians.

\subsection{PK DIs and clinical implications}

Carbamazepine, phenobarbital, phenytoin and primidone are potent inducers that are likely to have clinically relevant effects on several antidepressant levels (Table 3). Adding any of these inducers (in the absence of other inducers) may be associated with a decrease in antidepressant plasma concentration that may be associated with lack of efficacy. The discontinuation of these inducers (when other inducers are not prescribed) may be associated with an increase in plasma antidepressant concentration that may be associated with ADRs. As antidepressant TDM may not be developed for some new antidepressants or clinicians may not have access to it in their clinical practices, Table 4 provides estimates for correction factors based on the limited available literature. A major problem is the absence of studies of the effect of potent inducers with agomelatine, desvenlafaxine, duloxetine, escitalopram, levomilnacipran, reboxetine, sertraline, venlafaxine, vilazodone, and vortioxetine. Antidepressants mainly dependent for their metabolism on CYP3A4 such as reboxetine or vilazodone may be particularly sensitive to induction. According to data from antipsychotics dependent on CYP3A4, they may require a correction factor of at least 5 [28].

The pharmacokinetic DIs associated with mild CYP3A4 inducers, such as clobazam, eslicarbazepine, oxcarbazepine, rufinamide and topiramate (Table 4), are not likely to be clinically relevant in most patients taking antidepressants, but it cannot be ruled out that in some unusual patients they may have clinical relevance. In that sense, clinicians may need to be watchful when using high doses of oxcarbazepine ( $\geq 1200 \mathrm{mg} /$ day) or topiramate ( $\geq 400 \mathrm{mg} /$ day), particularly with 
antidepressants that require important dose corrections, when using potent inducers such as mirtazapine and TCAs, or those mainly metabolized by CYP3A4 such as reboxetine or vilazodone. Antidepressant DI studies should consider that valproic acid may not be an inhibitor of some metabolic enzymes, but a mild inducer of other metabolic enzymes or transporters, or behave both as a mild inducer and a competitive inhibitor [70].

Fluoxetine and fluvoxamine are relevant inhibitors of phenytoin and valproic acid, but the literature does not provide information on calculating dose correction factors. Therefore, fluoxetine and fluvoxamine should not be added or discontinued from patients taking phenytoin or valproic acid without close monitoring of the antiepileptic TDM. Other not-well-studied antiepileptics likely to be influenced by the inhibitory effects of fluoxetine or fluvoxamine are those dependent on CYP2C9 or CYP2C19 for their metabolism, including clobazam, lacosamide, phenobarbital, or primidone. Fluoxetine may take up to 2-3 months in an average patient (or even up to 6 months in unusual patients) to reach maximal inhibitory effects on CYP3A4 due to the long half-life of norfluoxetine, so it may be important to remember that when co-prescribing fluoxetine with antiepileptics dependent on CYP3A4 such as carbamazepine, felbamate, tiagabine, or zonisamide. Table 4 reports that it may be safer to select antidepressants other than fluoxetine or fluvoxamine when taking any of these antiepileptics. Isolated cases have suggested that it may be safer to avoid fluoxetine and sertraline in patients taking lamotrigine (Table 4). Studies of high doses of sertraline should rule out that it inhibits valproate and/or lamotrigine metabolism. In vitro studies suggest that TCAs (Table 2) are moderate CYP2C19 inhibitors; therefore, TCAs have potential for inhibiting the metabolism of some antiepileptics including lacosamide and clobazam's main metabolite.

\subsection{PD DIs and clinical implications}

In our experience, pharmacodynamic DIs are very relevant in clinical practice (Table 4). Five unstudied pharmacodynamic DIs may prove beneficial by increasing efficacy (Table 4): i) the possible additive effects for generalized anxiety disorder when adding pregabalin to an antidepressant, ii) the possible additive effects for chronic pain when combining some antiepileptics (carbamazepine, gabapentin, oxcarbazepine, or pregabalin) with SNRIs or TCAs, iii) the possible additive effects for migraine prophylaxis when combining topiramate or valproic acid with TCAs (particularly amitriptyline) or venlafaxine, iv) the possible additive effects for weight control when combining bupropion and zonisamide (or topiramate), and v) the possible additive effects for menopausal symptoms when combining gabapentin with SNRIs or SSRIs.

Two pharmacodynamic DIs may cause harm by decreasing efficacy (Table 4): i) some antiepileptics, (Table 4) particularly phenobarbital, primidone, topiramate, and vigabatrin have 
been associated with depression and should be avoided in patients with that vulnerability; and ii) bupropion and TCAs should be avoided in patients with epilepsy due to the risk of decreasing the seizure threshold. The controversial issue of adding antidepressants for bipolar depression has been described in Section 3.2.2.

Two unstudied PD DIs have the potential to be beneficial by increasing safety (Table 4): i) topiramate and zonisamide may decrease the effect on weight of antidepressants associated with weight gain (amitriptyline, mirtazapine, paroxetine), and ii) rufinamide may decrease QTc in patients with SSRIs. Fluoxetine has been associated with in vitro effects of anticonvulsant properties but has major potential for pharmacokinetic DIs. It is not clear whether other SSRIs share those anticonvulsant properties. Bupropion and TCAs clearly decrease the seizure threshold.

Five additive (or synergistic) DIs with increased risk for common ADRs include increased risk for sedation, weight gain, hyperlipidemia, nausea, and urinary retention. Table 4 describes the specific combinations, along with these increased safely risks. Finally, Table 4 describes five potentially lethal PD DIs: hyponatremia, torsades de pointes, hepatic failure, hemorrhages, and heat stroke. These ADRs are very rare and we are not sure that antiepileptic-antidepressant combinations increase their risk but pharmacological mechanisms suggest that possibility, and clinicians need to remember the potential for PD Dis in order to prevent or quickly diagnose them.

Finally, long-term treatment with antiepileptics that are potent inducers is definitively associated with osteoporosis. Recent studies, which may take many years for definitive confirmation, suggest that mild inducers, such as oxcarbazepine, topiramate or valproic acid, and SSRIs may be associated with osteoporosis. Clinicians may want to consider the possible increased risks when combining SSRIs with these mild inducers over many years.

\section{Expert opinion}

The pharmacological mechanisms and clinical relevance of DIs associated with the inductive properties of carbamazepine, phenytoin, phenobarbital and primidone and the inhibitory properties of valproate and some antidepressants are well understood while pharmacokinetic DI studies with new antiepileptics and new antidepressants are limited. It appears safer to overwarn clinicians about the potential risks of losing efficacy when adding inducers or of increased ADRs when adding inhibitors, as well as the risks of ADRs when discontinuing inducers or losing efficacy when discontinuing inhibitors. Clinicians cannot afford to wait for definitive studies, which are not likely to happen once the new drugs are already marketed. Table 4 provides correction factors calculated using the available PK studies, assuming that the average patient represents the population well. However, there is extensive PK variability among patients, and TDM 
measurements should be advised for optimal titration of the dosage in each individual. These limited correction factors are useful because: i) many clinicians have no access to TDM; ii) there is limited clinical data on TDM for new compounds; and iii) having the correction factor helps clinicians to make decisions to use safer drugs. With a correction factor of 10 , bupropion is a very poor antidepressant choice for patients taking antiepileptics with powerful inductive properties. There will be a need to periodically update these correction factors as new knowledge becomes available.

Using the limited available information, the authors believe that in high doses oxcarbazepine ( $\geq 1200 \mathrm{mg} /$ day) and topiramate ( $\geq 400 \mathrm{mg} /$ day) may be clinically relevant CYP3A4 inducers and possible inducers of some UGTs. It is possible that clobazam, eslicarbazepine, and rufinamide may also be dose-dependent CYP3A4 inducers. Two other mild inducers, felbamate and vigabatrin, are rarely prescribed. More problematic is the case of valproic acid, a drug traditionally considered a potential inhibitor, which may also be a dose-dependent mild inducer of some antipsychotics. The metabolic enzymes and/or transporters influenced by valproic acid induction are not known. These metabolic enzymes and/or transporters may also be subject to competitive inhibition by valproic acid [70]. As described earlier, valproic acid may also a vitamin D inducer [45].

It is not easy to conduct DI studies using clinically relevant doses of inducers or inhibitors. Pharmaceutical companies tend to invest in simple PK DI studies in volunteers, frequently using single dosing to get approval for the marketing of their drugs, but this type of PK study rarely reflects clinical practice. The DI material in prescribing information (or package inserts) is usually not designed to provide easy helps for clinicians to correct PK DIs with dose changes. It appears naïve to criticize the PK science on antiepileptic-antidepressant combinations; at least there is some PK data. There is almost no PD science on antiepileptic-antidepressant combinations. The potential PD DIs described in Table 4 were developed after reviewing known pharmacological mechanisms, efficacy and ADRs in antiepileptic or antidepressant studies. There are almost no studies of the potential synergistic or additive benefits of combining antiepileptics and antidepressants for generalized anxiety disorder, pain, migraine prophylaxis, weight and menopausal symptoms. The lack of studies in OCD is an even more problematic case. Some studies have used adjuvant antiepileptics such as lamotrigine for patients who did not sufficiently respond to SSRIs [121]. OCD guidelines usually recommend SSRIs as first-line, followed by augmentation with clomipramine and/or antipsychotics, but there is no information for clinicians on what to do when all three treatments have been tried. Patients resistant to these three steps are usually very impaired and not likely to recover spontaneously, or have placebo response [154]. It would be ideal to complete RCTs with adjunctive treatment with lamotrigine or topiramate, but the great severity of 
this type of treatment-refractory patients make them unlikely to take part in RCTs. This is a good example of a generalized problem in clinical practice: the more difficult the patient, the less information is available to guide the treatment. In difficult patients, clinicians frequently use drug combinations in the absence of good information on their risk/benefit; moreover, they prefer combinations to monotherapy.

Clinicians use antiepileptic-antidepressant combinations frequently in patients for anxiety disorder, pain, migraine prophylaxis, weight and menopausal symptoms, looking for greater efficacy, and for depression in the presence of any primary indications for antiepileptics such as epilepsy. There is obviously more need for studies of PK and PD DI between antiepileptics and antidepressants, but the lack of funding for clinical research is a major limitation. Collaboration from all interested parties is needed, including: i) drug agencies and pharmaceutical companies; ii) clinicians using antiepileptic-antidepressant combinations; iii) researchers with expertise in a) metaanalyses, b) pharmacoepidemiology, and c) DI pharmacology; and iv) grant agencies.

Drug agencies should be more insistent upon rapid approval for new antiepileptics with PD mechanisms analogous to those from already-approved compounds and with less risk for PK DIs. Oxcarbazepine and eslicarbazepine are likely to have efficacy in the same disorders as carbamazepine. It may be a good idea for drug agencies to facilitate and simplify an efficacy study as a long-term PK study with high doses and enough time duration to establish the real potential for induction of these compounds. There are analogs of valproic acid in development for epilepsy but it will be important to establish that they have better pharmacokinetic DIs and less toxicity than valproic acid for non-epileptic indications.

There is great need for naturalistic studies by clinicians describing the possible additive or synergistic effects related to the efficacy and safety of the antiepileptic-antidepressant combinations. Are early sedation or early nausea and vomiting more frequent in some of these combinations than in the various monotherapies? Is osteoporosis a long-term issue in vulnerable patients taking mild antiepileptic inducers and SSRIs for years?

Researchers with expertise in meta-analysis may need to be ready to analyze the efficacy and safety of antiepileptic-antidepressant combinations, comparing them to studies of the drugs individually. Researchers with expertise in pharmacoepidemiology need to explore whether rare, but potentially lethal, ADRs such as hyponatremia, torsades de pointes, hepatic failure; hemorrhages, and heat stroke may be more frequently associated with using antiepilepticantidepressant combinations than with individual drugs. Researchers with expertise in in vitro DI studies or in vivo clinical studies using isotopes to explore drug clearance need to better study the new antiepileptics' and the new antidepressants' metabolic pathways and how they change when 
inhibitors, such as valproic acid or SSRIs, and inducers, such as high doses of mild inducers, are added.

Grant and health agencies need to remember that pragmatic clinical trials are key in treating complex disorders such as epilepsy, bipolar disorder, chronic pain or in preventing migraines where polytherapy is the norm. Pharmaceutical RCTs do not substitute for long-term pragmatic trials that may better inform clinicians of the effectiveness of the various types of mono- and polytherapy frequently used in the real world of clinical practice. Pragmatic trials need to pay better attention to DIs.

Knowledge of DIs is becoming more complex, since even antiepileptic mild inducers may have clinically relevant PK DIs. Progress in the next few years may not be guaranteed even if this ambitious research agenda is followed, unless it is accompanied by a better continuous medical education concerning DIs and improvements in neuropsychopharmacology textbooks, so that clinicians begin to pay more attention to PD and PK DIs associated with the frequent coprescription of antiepileptic-antidepressant combinations. The authors would like to see welleducated clinicians assist in pushing this research agenda forward by publishing DI case reports of unusual combinations and asking for more DI studies from pharmaceutical companies and researchers. 


\section{References}

1. Johannessen Landmark C. Antiepileptic drugs in non-epilepsy disorders: relations between mechanisms of action and clinical efficacy. CNS Drugs 2008;22:27-47

2. Bialer M. Why are antiepileptic drugs used for nonepileptic conditions? Epilepsia 2012;53(Suppl 7):26-33

3. Marson AG, Al-Kharusi AM, Alwaidh M, et al. The SANAD study of effectiveness of valproate, lamotrigine, or topiramate for generalised and unclassifiable epilepsy: an unblinded randomised controlled trial. Lancet 2007;369:1016-26

4. Marson AG, Al-Kharusi AM, Alwaidh M, et al. The SANAD study of effectiveness of carbamazepine, gabapentin, lamotrigine, oxcarbazepine, or topiramate for treatment of partial epilepsy: an unblended randomised controlled trial. Lancet 2007;369:1000-15

5. Stahl SM. Antidepressants. In: Stahl SM, editor. Stahl's Essential Psychopharmacology. 4th ed. Cambridge University Press, New York; 2013. p. 284-369

6. Hermann B, Seidenberg M, Bell B. Psychiatric comorbidity in chronic epilepsy: identification, consequences, and treatment of major depression. Epilepsia 2000;41:S31S41

7. Prueter C, Norra C. Mood disorders and their treatment in patients with epilepsy. J Neuropsychiatry Clin Neurosci 2005;17:20-8

8. Mula M, Schmitz B, Sander WJ. The pharmacological treatment of depression in adults with epilepsy. Expert Opin Pharmacother 2008;9:3159-68

9. Mula M, Schmitz B. Depression in epilepsy: mechanisms and therapeutic approach. Ther Adv Neurol Disord 2009;2:337-44

10. Kanner AM. The treatment of depressive disorders in epilepsy: What all neurologists should know. Epilepsia 2013;54:3-12

11. Mehndiratta P, Sajatovic M. Treatments for patients with comorbid epilepsy and depression: A systematic literature review. Epilepsy Behav 2013;28:36-40

12. Harden CL, Goldstein MA. Mood disorders in patients with epilepsy: epidemiology and management. CNS Drugs 2002;16:291-302

13. Geddes JR, Miklowitz DJ. Treatment of bipolar disorder. Lancet 2013;381:1672-82

14. Grunze HC. Anticonvulsants in bipolar disorder. J Ment Health 2010;19:127-41

15. Vieta E, Valentí M. Pharmacological management of bipolar depression: acute treatment, maintenance, and prophylaxis. CNS Drugs 2013;27:515-29

16. Mula M. Investigating psychotropic properties of antiepileptic drugs. Expert Rev Neurother 2013;13:639-46 
17. Tan T, Barry P, Reken S, Baker M; Guideline Development Group. Pharmacological management of neuropathic pain in non-specialist settings: summary of NICE guidance. BMJ 2010;340:c1079

18. Dworkin RH, O'Connor AB, Audette J, et al. Recommendations for the pharmacological management of neuropathic pain: an overview and literature update. Mayo Clin Proc 2010;85:S3-14

19. Chaparro LE, Wiffen PJ, Moore RA, Gilron I. Combination pharmacotherapy for the treatment of neuropathic pain in adults. Cochrane Database Syst Rev 2012;7:CD008943

20. Rickels K, Shiovitz TM, Ramey TS, et al. Adjunctive therapy with pregabalin in generalized anxiety disorder patients with partial response to SSRI or SNRI treatment. Int Clin Psychopharmacol 2012;27:142-50

21. Vitali M, Tedeschini E, Mistretta M, et al. Adjunctive pregabalin in partial responders with major depressive disorder and residual anxiety. J Clin Psychopharmacol 2013;33:95-8

22. Casucci G, Villani V, Cologno D, D'Onofrio F. Polytherapy for migraine prophylaxis. Neurol Sci 2012;33:S147-50

23. Silberstein SD, Holland S, Freitag F, et al. Evidence-based guideline update: pharmacologic treatment for episodic migraine prevention in adults: report of the Quality Standards Subcommittee of the American Academy of Neurology and the American Headache Society. Neurology 2012;78:1337-45

24. Patsalos PN, Perucca E. Clinically important drug interactions in epilepsy: general features and interactions between antiepileptic drugs. Lancet Neurol 2003;2:347-56

- Comprehensive review of clinically relevant drug interactions with antiepileptics.

25. Patsalos PN, Perucca E. Clinically important drug interactions in epilepsy: interactions between antiepileptic drugs and other drugs. Lancet Neurol 2003;2:473-81

- Comprehensive review of clinically relevant drug interactions with antiepileptics.

26. Perucca E. Clinically relevant drug interactions with antiepileptic drugs. $\mathrm{Br} \mathrm{J}$ Clin Pharmacol 2006;61:246-55

27. Johannesen Landmark C, Patsalos P. Drug interactions involving the new second- and thirdgeneration antiepileptic drugs. Expert Rev Neurother 2010;10:119-40

-• Comprehensive review of second-generation antiepileptic drug interactions.

28. de Leon J, Santoro V, D'Arrigo C, Spina E. Interactions between antiepileptics and secondgeneration antipsychotics. Exp Opin Drug Metab Toxicol 2012;8:311-34

-• Updated review of drug interactions between antiepileptics and second-generation antipsychotics using the same format of this article. 
29. Nemeroff CB, Preskorn S, Devane CL. Antidepressant drug-drug interactions: clinical relevance and risk management. CNS Spectr 2007;12:1-13

30. Schellander R, Donnerer J. Antidepressants: clinically relevant drug interactions to be considered. Pharmacology 2010;86:203-15

31. Spina E, Santoro V, D’Arrigo C. Clinically relevant pharmacokinetic drug interactions with second-generation antidepressants: an update. Clin Ther 2008;30:1206-27

- Comprehensive review of newer antidepressant drug interactions.

32. Spina E, Trifirò G, Caraci F. Clinically significant drug interactions with newer antidepressants. CNS Drugs 2012;26:39-67

-• Comprehensive review of the drug interactions of the most recently marketed antidepressants.

33. Spina E, de Leon J. Clinically relevant interactions between newer antidepressants and second-generation antipsychotics. Exp Opin Drug Metab Toxicol 2014; 10: 712-46

-• Updated review of drug interactions between newer antidepressants and second generation antipsychotics using the same format of this article.

34. Spina E, Perucca E. Clinical significance of pharmacokinetic interactions between antiepileptic and psychotropic drugs. Epilepsia 2002;43(Suppl 2):37-44

35. Mula M. Anticonvulsants-antidepressants pharmacokinetic drug interactions: the role of the CYP450 system in psychopharmacology. Curr Drug Metab 2008;8:730-7

36. DeVane CL. Clinical significance of drug binding, protein binding, and binding displacement drug interactions. Psychopharmacol Bull 2002;36:5-21

37. Spina E. Drug interactions. In: Shorvon S, Perucca E, Engel J, editors, Treatment of Epilepsy, 3rd ed. Wiley-Blackwell Publishing Ltd, Oxford; 2009. p. 361-77

38. Cozza KL, Armstrong SC, Oesterheld JR. Concise Guide to Drug interaction Principles for Medical Practice: Cytochrome P450s, UGTs, P-Glycoproteins. 2nd ed. American Psychiatric Association: Washington, DC, 2003

39. Shin JG, Park JY, Kim MJ, et al. Inhibitory effects of tricyclic antidepressants (TCAs) on human cytochrome P450 enzymes in vitro: mechanism of drug interaction between TCAs and phenytoin. Drug Metab Dispos 2002;30:1102-7

40. Lin JH. Transporter-mediated drug interactions. Clinical implications and in vitro assessment. Exp Opin Drug Metab Toxicol 2007;3:81-92

41. Zhang C, Kwan P, Zuo Z, Baum L. The transport of antiepileptic drugs by P-glycoprotein. Adv Drug Deliv Rev 2012;64:930-42 
42. O’Brien FE, Dinan TG, Griffin BT, Cryan JF. Interactions between antidepressants and Pglycoprotein at the blood-brain barrier: clinical significance of in vitro and in vivo findings. Br J Pharmacol 2012;165:289-312

43. Akamine Y, Yasui-Furukori N, Ieiri I, Uno T. Psychotropic drug-drug interactions involving P-glycoprotein. CNS Drugs 2012;26:959-73

44. Brodie MJ, Mintzer S, Pack AM, et al. Enzyme induction with antiepileptic drugs: Cause for concern? Epilepsia 2013;54:11-27

45. Vrzal R, Doricakova A, Novotna A, et al. Valproic acid augments vitamin D receptormediated induction of CYP24 by vitamin D3: a possible cause of valproic acid-induced osteomalacia? Toxicol Lett. 2011;200:146-53

46. Miziak B, Błaszczyk B, Chrościńska-Krawczyk M, et al. The problem of osteoporosis in epileptic patients taking antiepileptic drugs. Expert Opin Drug Saf 2014;13:935-46

47. de Leon J. Glucuronidation enzymes, genes and psychiatry. Int J Neuropsychopharmacol $2003 ; 6: 57-72$

48. Benedetti MS, Whomsley R, Baltes E, Tonner F. Alteration of thyroid hormone homeostasis by antiepileptic drugs in humans: involvement of glucuronosyltransferase induction. Eur $\mathrm{J}$ Clin Pharmacol 2005;61:863-72

49. Sheth RD, Montouris G. Metabolic effects of AEDs: impact on body weight, lipids and glucose metabolism. Int Rev Neurobiol 2008;83:329-46

50. Isojärvi JI, Taubøll E, Herzog AG. Effect of antiepileptic drugs on reproductive endocrine function in individuals with epilepsy. CNS Drugs 2005;19:207-23

51. Jakubus T, Michalska-Jakubus M, Lukawski K, et al. Atherosclerotic risk among children taking antiepileptic drugs. Pharmacol Rep 2009;61:411-23

52. Belcastro V, Striano P. Antiepileptic drugs, hyperhomocysteinemia and B-vitamins supplementation in patients with epilepsy. Epilepsy Res 2012;102:1-7

53. Hill DS, Wlodarczyk BJ, Palacios AM, Finnell RH. Teratogenic effects of antiepileptic drugs. Expert Rev Neurother 2010;10:943-59

54. Labbate LA, Fava M, Rosenbaum JF, et al. Handbook of Psychiatric Drug Therapy. Lippincott Williams \& Wilkins: Philadelphia, 2010

55. Venkatakrishnan K, Greenblatt DJ, von Moltke LL, et al. Five distinct human cytochromes mediate amitriptyline N-demethylation in vitro: dominance of CYP 2C19 and 3A4. J Clin Pharmacol 1998;38:112-21

56. Breyer-Pfaff U. The metabolic fate of amitriptyline, nortriptyline and amitriptylinoxide in man. Drug Metab Rev 2004;36:723-46 
57. Spina E, Avenoso A, Campo GM, et al. Phenobarbital induces the 2-hydroxylation of desipramine. Ther Drug Monit 1996;18:60-4

58. Spina E, Avenoso A, Campo GM, et al. The effect of carbamazepine on the 2-hydroxylation of desipramine. Psychopharmacology 1995;117:413-6

59. Szymura-Oleksiak J, Wyska E, Wasieczko A. Pharmacokinetic interaction between imipramine and carbamazepine in patients with major depression. Psychopharmacology $2001 ; 154: 38-42$

60. Greb WH, Buscher G, Dierdorf HD, et al. The effect of liver enzyme inhibition by cimetidine and enzyme induction by phenobarbitone on the pharmacokinetics of paroxetine. Acta Psychiatr Scand Suppl 1989;350:95-8

61. Andersen BB, Mikkelsen M, Vesterager A, et al. No influence of the antidepressant paroxetine on carbamazepine, valproate and phenytoin. Epilepsy Res 1991;10:201-4

62. Kahn A, Shad MU, Preskhorn SH. Lack of sertraline efficacy probably due to an interaction with carbamazepine. J Clin Psychiatry 2000;61:526-7

63. Steinacher L, Vandel P, Zullino DF, et al. Carbamazepine augmentation in depressive patients non-responding to citalopram: a pharmacokinetic and clinical pilot study. Eur Neuropsychopharmacol 2002;12:255-60

64. Puozzo C, Leonard BE. Pharmacokinetics of milnacipran in comparison with other antidepressants. Int Clin Psychopharmacol 1996;11(Suppl 4):15-27

65. Sitsen J, Maris F, Timmer C. Drug-drug interaction studies with mirtazapine and carbamazepine in healthy male subjects. Eur J Drug Metab Pharmacokinet 2001;26:109-21

66. Spaans E, van den Heuvel MW, Schnabel PG, et al. Concomitant use of mirtazapine and phenytoin: a drug-drug interactions study in healthy male subjects. Eur J Clin Pharmacol 2002;58:423-9

67. Ketter TA, Jenkins JB, Schroeder DH, et al. Carbamazepine but not valproate induces bupropion metabolism. J Clin Psychopharmacol 1995;15:327-33

68. Helland A, Spigset O. Low serum concentrations of reboxetine in 2 patients treated with CYP3A4 inducers. J Clin Psychopharmacol 2007;27:308-10

69. Cerveny L, Svecova L, Anzenbacherova E, et al. Valproic acid induces CYP3A4 and MDR1 gene expression by activation of constitutive androstane receptor and pregnane $\mathrm{X}$ receptor pathways. Drug Metab Dispos 2007;35:1032-41

70. de Leon J. False-negative studies may systematically contaminate the literature on the effects of inducers in neuropsychopharmacology. Part II: focus on bipolar disorder. J Clin Psychopharmacol 2014;34:291-6 
71. Vandel S, Bertschy G, Jounet JM, et al. Valpromide increases the plasma concentrations of amitriptyline and its metabolite nortriptyline in depressive patients. Ther Drug Monit $1988 ; 10: 386-9$

72. Bertschy G, Vandel S, Jounet JM, Allers G. Valpromide-amitriptyline interaction: Increase in the bioavailability of amitriptyline and nortriptyline caused by valpromide. Encephale $1990 ; 16: 43-5$

73. Wong SL, Cavanaugh J, Shi H, et al. Effects of divalproex sodium on amitriptyline and nortriptyline pharmacokinetics. Clin Pharmacol Ther 1996;60:48-53

74. Fu C, Katzman M, Goldbloom DS. Valproate/nortriptyline interaction. J Clin Psychopharmacol 1994;14:205-6

75. Fehr C, Grunder G, Hiemke C, Dahmen N. Increase of serum clomipramine concentrations caused by valproate. J Clin Psychpharmacol 2000;20:493-4

76. Avoni P, Riva R, Albani F. Recurrence of absence seizures induced by a low dose of amitriptyline. Eur J Neurol 1996;3:272-4

77. DeToledo JC, Haddad H, Ramsay RE. Status epilepticus associated with the combination of valproic acid and clomipramine. Ther Drug Monit 1997;19:71-3

78. Roberts-Thomson KC, Teo KS, Young GD. Drug-induced Brugada syndrome with ST-T wave alternans and long QT. Intern Med J 2007;37:199-200

79. Unterecker S, Burger R, Hohage A, et al. Interaction of valproic acid and amitriptyline: analysis of therapeutic drug monitoring data under naturalistic conditions. J Clin Psychopharmacol 2013;33:561-4

80. Unterecker S, Reif A, Hempel S, et al. Interaction of valproic acid and the antidepressants doxepin and venlafaxine: analysis of therapeutic drug monitoring data under naturalistic conditions. Int Clin Psychopharmacol 2014;29:206-11

81. Kirchheiner J, Meineke I, Muller G, et al. Contributions of CYP2D6, CYP2C9 and CYP2C19 to the biotransformation of E- ad Z-doxepin in healthy volunteers. Pharmacogenetics 2002;12:571-80

82. Fogelman SM, Schmider J, Venkatakrishnan K, et al. O- and N-demethylation of venlafaxine in vitro by human liver microsomes from cDNA-transfected cells: effect of metabolic inhibitors and SSRI antidepressants. Neuropsychopharmacology 1999;20:480-90

83. Baird P. The interactive metabolism effect of oxcarbazepine coadministered with tricyclic antidepressant therapy for OCD symptoms. J Clin Psychopharmacol 2003;23:419-20

84. Hemeryck A, Belpaire FM. Selective serotonin reuptake inhibitors and cytochrome P-450 mediated drug-drug interactions: an update. Curr Drug Metab 2002;3:13-37 
85. Jalil P. Toxic reaction following the combined administration of fluoxetine and phenytoin: two case reports. J Neurol Neurosurg Psychiatry 1992;55:412-3

86. Darley J. Interaction between phenytoin and fluoxetine. Seizure 1994;3:151-2

87. Woods DJ, Coulter DM, Pillans P. Interaction of phenytoin and fluoxetine. NZ Med J 1994; 107:19

88. Shader RI, Greenblatt DJ, Von Moltke LL. Fluoxetine inhibition of phenytoin metabolism. J Clin Psychopharmacol 1994;14:375-6

89. Pearson HJ. Interaction of fluoxetine with carbamazepine. J Clin Psychiatry 1990;51:126

90. Grimsley SR, Jann MW, Carter JG, et al. Increased carbamazepine plasma concentrations after fluoxetine coadmnistration. Clin Pharmacol Ther 1991;50:10-5

91. Spina E, Avenoso A, Pollicino AM, et al. Carbamazepine coadministration with fluoxetine or fluvoxamine. Ther Drug Monit 1993;15:247-50

92. Sovner R, Davis JM. A potential drug interaction between fluoxetine and valproic acid. J Clin Psychopharmacol 1991;11:389

93. Cruz-Flores S, Hayat GR, Mirza W. Valproic acid toxicity with fluoxetine therapy. Mo Med 1995;92:296-7

94. Lucena MI, Blanco E, Corrales MA, Berthier ML. Interaction of fluoxetine and valproic acid. Am J Psychiatry 1998;155:575

95. Reimers A, Skogvoll E, Sund JK, Spigset O. Drug interaction between lamotrigine and psychoactive drugs. J Clin Psychopharmacol 2005;25:342-8

96. Fritze J, Unsorg B, Lanczik M. Interaction between carbamazepine and fluvoxamine. Acta Psychiatr Scand 1991;84:583-4

97. Bonnet P, Vandel S, Nezelof S, et al. Carbamazepine, fluvoxamine. Is there a pharmacokinetic interaction? Therapie 1992;47:165

98. Mamiya K, Kojima K, Yukawa E, et al. Phenytoin intoxication induced by fluvoxamine. Ther Drug Monit 2001;23:75-7

99. Rapeport WG, Muirhead DC, Williams SA, et al. Absence of effect of sertraline on the pharmacokinetics and pharmacodynamics of phenytoin. J Clin Psychiatry 1996;57(Suppl 1): 24-8

100. Rapeport WG, Williams SA, Muirhead DC, et al. Absence of sertraline-mediated effect of the pharmacokinetics and pharmacodynamics of carbamazepine. J Clin Psychiatry 1996;57(suppl.1):20-3

101. Berigan TR, Harazin J. A sertraline/valproic acid drug interaction. Int J Psychiatr Clin Pract 1999;3:287-88 
102. Kaufman KR, Gerner R. Lamotrigine toxicity secondary to sertraline. Seizure $1998 ; 7: 163-5$

103. Christensen J, Sandgaard AP, Sidenius P, et al. Lack of interaction between sertraline and lamotrigine in psychiatric patients: a retrospective study. Pharmacopsychiatry 2012;45:119-21

104. Von Moltke LL, Greenblatt DJ, Grassi JM, et al. Citalopram and desmethylcitalopram in vitro: human cytochromes mediating transformation, and cytochrome inhibitory effects. Biol Psychiatry 1999;46:839-44

105. Von Moltke LL, Greenblatt DJ, Giancarlo GM, et al. Escitalopram (S-citalopram) and its metabolites in vitro: cytochromes mediating biotransformation, inhibitory effects, and comparison to R-citalopram. Drug Metab Dispos 2001;29:1102-9

106. Moller SE, Larsen F, Khan AZ, Rolan PE. Lack of effect of citalopram on the steady-state pharmacokinetics of carbamazepine in healthy male subjects. J Clin Psychopharmacol 2001;21:493-9

107. Popli AP, Tanquary J, Lamparella V, Masand PS. Bupropion and anticonvulsant drug interactions. Ann Clin Psychiatry 1995;7:99-101

108. Odishaw J, Chen C. Effects of steady-state bupropion on the pharmacokinetics of lamotrigine in healthy subjects. Pharmacotherapy 2000;20:1448-53

109. Vigo DV, Baldessarini RJ. Anticonvulsants in the treatment of major depressive disorder: an overview. Harv Rev Psychiatry 2009;17:231-41

110. Malhi GS, Hitching R, Berk M, et al. Pharmacological management of unipolar depression. Acta Psychiatr Scand Suppl. 2013;443:6-23

111. Baldwin DS, Anderson IM, Nutt DJ, et al. Evidence-based pharmacological treatment of anxiety disorders, post-traumatic stress disorder and obsessive-compulsive disorder: A revision of the 2005 guidelines from the British Association for Psychopharmacology. J Psychopharmacol 2014;28:403-39

112. O'Connor AB, Dworkin RH. Treatment of neuropathic pain: an overview of recent guidelines. Am J Med 2009;122:S22-32

113. Gilron I, Bailey $\mathrm{JM}, \mathrm{Tu} \mathrm{D}$, et al. Nortriptyline and gabapentin, alone and in combination for neuropathic pain: a double-blind, randomised controlled crossover trial. Lancet 2009;374:1252-61

114. Nishihara M, Arai YC, Yamamoto Y, et al. Combinations of low-dose antidepressants and low-dose pregabalin as useful adjuvants to opioids for intractable, painful bone metastases. Pain Physician 2013;16:E547-52 
115. Pringsheim T, Davenport WJ, Becker WJ. Prophylaxis of migraine headache. CMAJ 2010;182:E269-76

116. Shamliyan TA, Choi JY, Ramakrishnan R, et al. Preventive pharmacologic treatments for episodic migraine in adults. J Gen Intern Med 2013;28:1225-37

117. Jackson JL, Shimeall W, Sessums L, et al. Tricyclic antidepressants and headaches: systematic review and meta-analysis. BMJ 2010;341:c5222

118. Krymchantowski AV, Jevoux C, Bigal ME. Topiramate plus nortriptyline in the preventive treatment of migraine: a controlled study for non responders. J Headache Pain 2012;13:53-9

119. Ioannides-Demos LL, Piccenna L, McNeil JJ. Pharmacotherapies for obesity: past, current, and future therapies. J Obes 2011;2011:179674

120. Bordeleau L, Pritchard KI, Loprinzi CL, et al. Multicenter, randomized, cross-over clinical trial of venlafaxine versus gabapentin for the management of hot flashes in breast cancer survivors. J Clin Oncol 2010;28:5147-52

121. Bruno A, Micò U, Pandolfo G, et al. Lamotrigine augmentation of serotonin reuptake inhibitors in treatment-resistant obsessive-compulsive disorder: a double-blind, placebocontrolled study. J Psychopharmacol 2012;26:1456-62

122. Vieta E, Günther O, Locklear J, et al. Effectiveness of psychotropic medications in the maintenance phase of bipolar disorder: a meta-analysis of randomized controlled trials. Int Neuropsychopharmacol 2011;14:1029-49

123. Pacchiarotti I, Bond DJ, Baldessarini RJ, et al. The International Society for Bipolar Disorders (ISBD) task force report on antidepressant use in bipolar disorders. Am J Psychiatry 2013;170:1249-62

124. Tondo L, Vázquez G, Baldessarini RJ. Mania associated with antidepressant treatment: comprehensive meta-analytic review. Acta Psychiatr Scand 2010;121:404-14

125. Köhler S, Gaus S, Bschor T. The challenge of treatment in bipolar depression: evidence from clinical guidelines, treatment recommendations and complex treatment situations. Pharmacopsychiatry 2014;47:53-9

126. Köster M, Grohmann R, Engel RR, et al. Seizures during antidepressant treatment in psychiatric inpatients--results from the transnational pharmacovigilance project "Arzneimittelsicherheit in der Psychiatrie" (AMSP) 1993-2008. Psychopharmacology (Berl) $2013 ; 230: 191-201$ 
127. Alper K, Schwartz KA, Kolts RL, Khan A. Seizure incidence in psychopharmacological clinical trials: an analysis of Food and Drug Administration (FDA) summary basis of approval reports. Biol Psychiatry 2007;62:345-54

128. Borowicz KK, Piskorska B, Stępniak B, Czuczwar SJ. Effects of fluoxetine on the anticonvulsant action of valproate and ethosuximide in mouse model of myoclonic convulsions. Ann Agric Environ Med 2012;19:487-90

129. Foianini A, Joseph Wiegand T, Benowitz N. What is the role of lidocaine or phenytoin in tricyclic antidepressant-induced cardiotoxicity? Clin Toxicol (Phila) 2010;48:325-30

130. Schimpf R, Veltmann C, Papavassiliu T, et al. Drug-induced QT-interval shortening following antiepileptic treatment with oral rufinamide. Heart Rhythm 2012;9:776-81

131. Serretti A, Mandelli L. Antidepressants and body weight: a comprehensive review and meta-analysis. J Clin Psychiatry 2010;71:1259-72

132. Nicholas LM, Ford AL, Esposito SM, et al. The effects of mirtazapine on plasma lipid profiles in healthy subjects. J Clin Psychiatry 2003;64:883-9

133. Cramer JA. Tolerability of antiepileptic drugs: can we determine differences? Epilepsy Behav 2012;23:187-92

134. Zaccara G, Giovannelli F, Maratea D, et al. Neurological adverse events of new generation sodium blocker antiepileptic drugs. Meta-analysis of randomized, double-blinded studies with eslicarbazepine acetate, lacosamide and oxcarbazepine. Seizure 2013;22:528-36

135. Gartlehner G, Hansen RA, Thieda P, et al. Comparative Effectiveness of Secondgeneration Antidepressants in the Pharmacologic Treatment of Adult Depression. Comparative Effectiveness. Review No. 7-EHC007-EF. Rockville, MD: Agency for Healthcare Research and Quality, 2007. Available at http://www.effectivehealthcare.ahrq.gov/repFiles/Antidepressants_Final_Report.pdf [Last accessed 25 June 2014]

136. Talley NJ. Functional nausea and vomiting. Aust Fam Physician. 2007;36:694-7

137. Alam A, Voronovich Z, Carley JA. A review of therapeutic uses of mirtazapine in psychiatric and medical conditions. Prim Care Companion CNS Disord 2013;15(5) doi: 10.4088/PCC.13r01525

138. Brickel N, Gandhi P, VanLandingham K, et al. The urinary safety profile and secondary renal effects of retigabine (ezogabine): a first-in-class antiepileptic drug that targets KCNQ (K(v)7) potassium channels. Epilepsia 2012;53:606-12 
139. Mago R, Mahajan R, Thase ME. Medically serious adverse effects of newer antidepressants. Curr Psychiatry Rep 2008;10:249-57

140. Dong X, Leppik IE, White J, Rarick J. Hyponatremia from oxcarbazepine and carbamazepine. Neurology 2005;65:1976-8

141. Lange-Asschenfeldt C, Kojda G, Cordes J, et al. Epidemiology, symptoms, and treatment characteristics of hyponatremic psychiatric inpatients. J Clin Psychopharmacol 2013;33:799-805

142. Postema PG, Wolpert C, Amin AS, et al. Drugs and Brugada syndrome patients: review of the literature, recommendations, and an up-to-date website (www.brugadadrugs.org). Heart Rhythm 2009;6:1335-41

143. Kogut C, Breden Crouse E, Vieweg V, et al. Selective serotonin reuptake inhibitors and torsade de pointes: new concepts and new directions derived from a systematic review of cases reports. Ther Adv in Drug Saf 2013;4:189-98

144. Johannesen L, Vicente J, Gray RA, et al. Improving the assessment of heart toxicity for all new drugs through translational regulatory science. Clin Pharmacol Ther 2014;15:501-8

145. Gahr M, Freudenmann RW, Connemann BJ, et al. Agomelatine and hepatotoxicity: implications of cumulated data derived from spontaneous reports of adverse drug reactions. Pharmacopsychiatry 2013;46:214-20

146. Voican CS, Corruble E, Naveau S, Perlemuter G. Antidepressant-induced liver injury: a review for clinicians. Am J Psychiatry 2014;171:404-15

147. Andrade C, Sandarsh S, Chethan KB, Nagesh KS. Serotonin reuptake inhibitor antidepressants and abnormal bleeding: a review for clinicians and a reconsideration of mechanisms. J Clin Psychiatry 2010;71:1565-75

148. Köse G, Arhan E, Unal B, et al. Valproate-associated coagulopathies in children during short-term treatment. J Child Neurol 2009;24:1493-8

149. Cheshire WP, Fealey RD. Drug-induced hyperhidrosis and hypohidrosis: incidence, prevention and management. Drug Saf 2008;31:109-26

150. United States Food and Drug Administration. Antidepressant use in children, adolescents, and young adults. 2007 Revisions to product labeling. Available at: http://www.fda.gov/downloads/Drugs/DrugSafety/InformationbyDrugClass/UCM173233.p df [Last accessed 25 June 2014]

151. US Department of Mental Health and Human Services. (2008). Statistical review and evaluation: Antiepileptic drugs and suicidality. Available at: 
http://www.fda.gov/ohrms/dockets/ac/08/briefing/2008-4372b1-01-FDA.pdf [Last accessed 25 June 2014]

152. Leon AC, Demirtas H, Li C, Hedeker D. Two propensity score-based strategies for a three-decade observational study: investigating psychotropic medications and suicide risk. Stat Med 2012;31:3255-60

153. Rizzoli R, Cooper C, Reginster JY, et al. Antidepressant medications and osteoporosis. Bone 2012;51:606-13

154. Arrojo-Romero M, Tajes Alonso M, de Leon J. Lamotrigine augmentation of serotonin reuptake inhibitors in severe and long-term treatment-resistant obsessivecompulsive disorder. Case Reports in Psychiatry 2013;2013:612459 doi: $10.1155 / 2013 / 612459$ 
Table 1. Pharmacokinetic parameters of antiepileptics. Based on [28, 37].

\begin{tabular}{|c|c|c|c|c|c|c|c|}
\hline & $\begin{array}{l}\text { Bioavail } \\
\text {-ability } \\
\text { (\%) }\end{array}$ & $\begin{array}{c}\text { Protein } \\
\text { binding } \\
\text { (\%) }\end{array}$ & $\begin{array}{l}\text { Half- } \\
\text { life (h) }\end{array}$ & $\begin{array}{l}\text { Most important } \\
\text { way of } \\
\text { elimination }^{1}\end{array}$ & Other ways of elimination & Active metabolites & \begin{tabular}{|l|} 
Induction or \\
inhibition of \\
metabolic enzymes
\end{tabular} \\
\hline \multicolumn{8}{|c|}{ FIRST GENERATION } \\
\hline Carbamazepine & $75-85$ & 75 & $5-26$ & $\mathrm{CYP}_{\mathrm{A}} 4^{2}$ & $\begin{array}{l}\text { CYP2C8, CYP1A2, } \\
\text { UGT2B7, epoxide hydrolase }\end{array}$ & $\begin{array}{l}\text { Carbamazepine } \\
\text { epoxide }\end{array}$ & $\begin{array}{l}\text { Induction of CYP1A2, } \\
\text { CYP2A6, CYP2B6, } \\
\text { CYP2C9, CYP2C19, } \\
\text { CYP3A4, UGT1A1, } \\
\text { UGT2B7, UGT2B15, } \\
\text { epoxide hydrolase }\end{array}$ \\
\hline Ethosuximide & $90-100$ & $<10$ & $25-70$ & ${\mathrm{CYP} 3 \mathrm{~A} 4^{2}}^{2}$ & CYP2E1, renal & & \\
\hline Phenytoin & 90 & 90 & $7-80$ & $\mathrm{CYP} 2 \mathrm{C}^{2}$ & $\begin{array}{l}\text { CYP2C19 (less important: } \\
\text { CYP2C18, CYP3A4) }\end{array}$ & & $\begin{array}{l}\text { Induction of CYP1A2, } \\
\text { CYP2B6, CYP2C8, } \\
\text { CYP2C9, CYP2C19, } \\
\text { CYP3A4, UGTs, } \\
\text { epoxide hydrolase }\end{array}$ \\
\hline Phenobarbital & $>95$ & $45-60$ & $70-130$ & $\mathrm{CYP}_{2 \mathrm{C}}{ }^{2}$ & $\begin{array}{l}\text { CYP2C19, CYP2E1, } \\
\text { N-glucosidation, renal }\end{array}$ & & $\begin{array}{l}\text { Induction of CYP1A2, } \\
\text { CYP2B6, CYP2C8, } \\
\text { CYP2C9, CYP2C19, } \\
\text { CYP2E1, CYP3A4, } \\
\text { UGT, epoxide } \\
\text { hydrolase }\end{array}$ \\
\hline Primidone & $>90$ & 10 & $5-20$ & CYP2C9 ${ }^{2}$ & $\begin{array}{l}\text { Renal, CYP2C19, CYP2E1, } \\
\text { N-glucosidation, }\end{array}$ & Phenobarbital & $\begin{array}{l}\text { Induction of CYP1A2, } \\
\text { CYP2B6, CYP2C8, } \\
\text { CYP2C9, CYP2C19, } \\
\text { CYP2E1, CYP3A4, } \\
\text { UGT, epoxide } \\
\text { hydrolase }\end{array}$ \\
\hline Valproate & $>90$ & $70-95$ & $8-16$ & Several UGTs & $\begin{array}{l}\beta \text {-oxidation, CYP2C9 (other } \\
\text { CYPs are minor) }\end{array}$ & & $\begin{array}{l}\text { Inhibition of CYP2C9, } \\
\text { UGT1A4, UGT2B7, } \\
\text { epoxide hydrolase, N- } \\
\text { glucosidation. }\end{array}$ \\
\hline
\end{tabular}




\begin{tabular}{|c|c|c|c|c|c|c|c|}
\hline & & & & & & & $\begin{array}{l}\text { Mild auto-induction } \\
\text { and mild induction of } \\
\text { other drugs }\end{array}$ \\
\hline \multicolumn{8}{|c|}{ SECOND GENERATION } \\
\hline Clobazam & $\sim 100$ & $80-90$ & $36-42$ & CYP3A4 ${ }^{2}$ & $\mathrm{CYP} 2 \mathrm{C} 19^{4}$ & $\begin{array}{l}\mathrm{N}- \\
\text { desmethylclobazam }\end{array}$ & $\begin{array}{l}\text { Mild induction of } \\
\text { CYP3A4 } \\
\text { Mild inhibition of } \\
\text { CYP2C19 and } \\
\text { CYP2D6 }\end{array}$ \\
\hline Eslicarbazepine & $\sim 100$ & 30 & $13-20$ & $\mathrm{UGTs}^{5}$ & Renal & S-licarbazepine & $\begin{array}{l}\text { Mild induction of } \\
\text { CYP3A4, UGTs. } \\
\text { Mild inhibition of } \\
\text { CYP2C9, CYP2C19 }\end{array}$ \\
\hline Felbamate & 90 & $20-25$ & $11-25$ & CYP3A4 $4^{2}$ & Renal, CYP2E1, UGTs & & $\begin{array}{l}\text { Mild induction of } \\
\text { CYP3A4 } \\
\text { Inhibition of } \\
\text { CYP2C19, } \beta \text { - } \\
\text { oxidation }\end{array}$ \\
\hline Gabapentin & $<65$ & 0 & $5-9$ & Renal & & & \\
\hline Lacosamide & $\sim 100$ & $<15$ & $12-16$ & CYP2C19 ${ }^{2}$ & Renal & & \\
\hline Lamotrigine & $>95$ & 55 & 25 & UGT1A4 & & & $\begin{array}{l}\text { Mild induction of } \\
\text { UGTs. }\end{array}$ \\
\hline Levetiracetam & 100 & $<10$ & $6-8$ & Renal & Esterase hydrolysis in blood & & \\
\hline Oxcarbazepine & $\sim 100$ & 40 & $7-12$ & Renal & UGTs & $\begin{array}{l}\text { MHD } \\
\text { (monohydroxy } \\
\text { derivate) }{ }^{6}\end{array}$ & $\begin{array}{l}\text { Mild induction of } \\
\text { CYP3A4, UGTs } \\
\text { Mild inhibition of } \\
\text { CYP2C19. }\end{array}$ \\
\hline Pregabalin & $>90$ & 0 & $5-7$ & Renal & & & \\
\hline $\begin{array}{l}\text { Retigabine } \\
\text { (ezogabine) }\end{array}$ & 60 & 80 & $8-10$ & $\begin{array}{l}\text { Arylamine N- } \\
\text { acetyl } \\
\text { transferase-2 }\end{array}$ & UGTs & & \\
\hline Rufinamide & 85 & 30 & $8-12$ & $\begin{array}{l}\text { Carboxyles- } \\
\text { terases }\end{array}$ & & & $\begin{array}{l}\text { Mild induction of } \\
\text { CYP3A4, UGTs }\end{array}$ \\
\hline
\end{tabular}




\begin{tabular}{|l|c|c|c|l|l|l|l|}
\hline & & & & & & $\begin{array}{l}\text { Mild inhibition of } \\
\text { CYP2E1. }\end{array}$ \\
\hline Stiripentol & $\geq 70$ & 99 & $4.5-13$ & & $\begin{array}{l}\text { CYP1A2, CYP2C19, } \\
\text { CYP3A4, UGTs }\end{array}$ & $\begin{array}{l}\text { Inhibition of CYP1A2, } \\
\text { CYP2C19, CYP2D6, } \\
\text { CYP3A4. }\end{array}$ \\
\hline Tiagabine & $\sim 100$ & 96 & $5-9$ & CYP3A4 ${ }^{7}$ & & $\begin{array}{l}\text { Mild induction of } \\
\text { CYP3A4, } \beta-\text {-oxidation, } \\
\text { UGT1A4. }\end{array}$ \\
\hline Topiramate & $\sim 100$ & $13-17$ & $10-30$ & Renal & CYP & $\begin{array}{l}\text { Mild inhibition of } \\
\text { CYP2C19. }\end{array}$ \\
\hline Vigabatrin & $\geq 50$ & 0 & $4-7$ & Renal & CYP (only 10\%) & $\begin{array}{l}\text { Mild induction of } \\
\text { CYP2C9. }\end{array}$ \\
\hline Zonisamide & $\sim 100$ & 50 & $50-70$ & CYP3A4 & $\begin{array}{l}\text { N-acetylation transferase, } \\
\text { renal }\end{array}$ & & \\
\hline
\end{tabular}

CYP: cytochrome P450; UGT: uridine diphosphate glucuronosyltransferase

${ }^{1}$ This refers to normal metabolism. Some subjects may not have this enzyme or have it inhibited. Other enzymes may become more important during induction.

${ }^{2}$ Any substrate competes with others for the corresponding enzyme and inhibits it (competitive inhibition). There is data in the literature that competitive inhibition may occur at CYP1A2, CYP2C9, CYP2C19, CYP2D6, and CYP3A4. UGTs tend to have overlapping substrates and it is not clear that they can be subject to competitive inhibition. A good example of competitive inhibition is phenytoin in high serum concentrations ( $>20 \mathrm{mcg} / \mathrm{ml}) \mathrm{which}$ may saturate completely or almost completely its metabolic enzymes, CYP2C9 and CYP2C19.

${ }^{3}$ Valproate has been demonstrated to have mild-autoinduction properties by inducing $\beta$-oxidation. Valproate may be an inducer of the metabolism of other medications including aripiprazole, clozapine, irinotecan and olanzapine but the induced enzymes are not established.

${ }^{4} \mathrm{~N}$-desmethlyclobazam is mainly metabolized by CYP2C19.

${ }^{5}$ Eslicarbazepine is a pro-drug that is activated by hepatic esterases to S-licarbazepine. S-licarbazepine is eliminated by UGTs and by the kidney (unchanged).

${ }^{6} \mathrm{MHD}$ is also called licarbazepine. Oxcarbazepine is a pro-drug and is activated by a cytosolic arylketone reductase that converts it to MHD, the active drug.

${ }^{7}$ There are four metabolic pathways. No specific enzyme can be considered a major enzyme. 
Table 2. Pharmacokinetic parameters of antidepressants. Based on [29, 31-33, 39].

\begin{tabular}{|c|c|c|c|c|c|c|c|}
\hline & $\begin{array}{l}\text { Bioavail- } \\
\text { ability } \\
\text { (\%) }\end{array}$ & $\begin{array}{l}\text { Protein } \\
\text { binding } \\
\text { (\%) }\end{array}$ & Half-life (h) & $\begin{array}{l}\text { Most } \\
\text { important way } \\
\text { of elimination }\end{array}$ & $\begin{array}{l}\text { Other ways of } \\
\text { elimination }\end{array}$ & Active metabolites & $\begin{array}{l}\text { Inhibitory effect on CYP } \\
\text { isoenzymes }\end{array}$ \\
\hline \multicolumn{8}{|l|}{$T C A$} \\
\hline Amitriptyline & $30-60$ & 96 & $10-50$ & $\begin{array}{l}\text { CYP2C19 and } \\
\text { CYP2D6 }\end{array}$ & $\begin{array}{l}\text { CYP1A2, CYP2C9, } \\
\text { CYP3A4 }\end{array}$ & Nortriptyline & $\begin{array}{l}\text { CYP2C19 (moderate) } \\
\text { CYP2D6 (weak) }\end{array}$ \\
\hline Clomipramine & 50 & $97-98$ & $19-37$ & $\begin{array}{l}\text { CYP2C19 and } \\
\text { CYP2D6 }^{2}\end{array}$ & $\begin{array}{l}\text { CYP1A2, CYP2C9, } \\
\text { CYP3A4 }\end{array}$ & Desmethylclomipramine & $\begin{array}{l}\text { CYP2C19 (moderate) } \\
\text { CYP2D6 (weak) }\end{array}$ \\
\hline Imipramine & 43 & $60-95$ & $8-20$ & $\begin{array}{l}\text { CYP2C19 and } \\
\text { CYP2D6 }^{2}\end{array}$ & $\begin{array}{l}\text { CYP1A2, CYP2C9, } \\
\text { CYP3A4 }\end{array}$ & Desipramine & $\begin{array}{l}\text { CYP2C19 (moderate) } \\
\text { CYP2D6 (weak) }\end{array}$ \\
\hline Nortriptyline & 51 & 93 & $16-38$ & CYP2D6 $^{2}$ & & & CYP2D6 (weak) \\
\hline \multicolumn{8}{|l|}{ SSRI } \\
\hline Citalopram & 95 & 82 & $23-45$ & CYP2C19 ${ }^{2}$ & CYP3A4, CYP2D6 & & CYP2D6 (weak) \\
\hline Escitalopram & 80 & 56 & 27 & CYP2C192 & \begin{tabular}{|l|} 
CYP3A4, CYP2D6 \\
\end{tabular} & & CYP2D6 (weak) \\
\hline Fluoxetine & 80 & 95 & 2-4 days & CYP2D6 $^{2}$ & $\begin{array}{l}\text { CYP2C9, CYP2C19, } \\
\text { CYP3A4 }\end{array}$ & Norfluoxetine & $\begin{array}{l}\text { CYP2D6 (potent) } \\
\text { CYP2C9 (moderate) } \\
\text { CYP2C19 and CYP3A4 } \\
\text { (weak to moderate) } \\
\text { CYP1A2 (weak) }\end{array}$ \\
\hline Fluvoxamine & $<53$ & 77 & $15-22$ & $\begin{array}{l}\text { CYP1A2, } \\
\text { CYP2D6 }\end{array}$ & & & $\begin{array}{l}\text { CYP1A2 and CYP2C19 } \\
\text { (potent) } \\
\text { CYP2C9 and CYP3A4 } \\
\text { (moderate) } \\
\text { CYP2D6 (weak) }\end{array}$ \\
\hline Paroxetine & $>64$ & 93 & $10-21$ & CYP2D6 $^{2}$ & CYP3A4 & & $\begin{array}{l}\text { CYP2D6 (potent) } \\
\text { CYP1A2, CYP2C9, } \\
\text { CYP2C19, CYP3A4 (weak) }\end{array}$ \\
\hline Sertraline & $>44$ & 98 & $22-36$ & CYP2B6 & $\begin{array}{l}\text { CYP2C19, CYP2C9, } \\
\text { CYP2D6, CYP3A4 }\end{array}$ & & $\begin{array}{l}\text { CYP2D6 (weak to } \\
\text { moderate) } \\
\text { CYP1A2, CYP2C9, } \\
\text { CYP2C19 and CYP3A4 } \\
\text { (weak) }\end{array}$ \\
\hline
\end{tabular}




\begin{tabular}{|c|c|c|c|c|c|c|c|}
\hline Desvenlafaxine & 80 & 30 & $9-15$ & Renal & UGT, CYP3A4 & & \\
\hline Duloxetine & 50 & $>90$ & $10-12$ & CYP1A2 $^{2}$ & CYP2D6 & & CYP2D6 (moderate) \\
\hline Levomilnacipran & 92 & 22 & 12 & Renal & UGT, CYP3A4 & & \\
\hline Milnacipran & 85 & 13 & $8-10$ & Renal & UGT, CYP3A4 & & CYP3A4 (weak) \\
\hline Venlafaxine & 92 & 27 & 5 & CYP2D6 $^{2}$ & CYP3A4 & Desvenlafaxine & \\
\hline \multicolumn{8}{|l|}{$\begin{array}{l}\text { Other newer } \\
\text { antidepressants }\end{array}$} \\
\hline Agomelatine & $<5$ & 95 & $1-2$ & ${\mathrm{CYP} 1 \mathrm{~A} 2^{2}}^{2}$ & CYP2C9 & & \\
\hline Bupropion & 90 & 84 & 20 & CYP2B6 & & $\begin{array}{l}\text { Hydroxybupropion } \\
\text { Threohydrobupropion } \\
\text { Erythrohydrobupropion }\end{array}$ & CYP2D6 (moderate) \\
\hline Mirtazapine & 50 & 85 & $20-40$ & $\begin{array}{l}\text { CYP2D6, } \\
\text { CYP3A4 }\end{array}$ & CYP1A2, UGTs & & \\
\hline Reboxetine & $>60$ & 97 & $12-16$ & CYP3A4 $^{2}$ & & & \\
\hline Trazodone & 65 & $89-95$ & $5-9$ & $\mathrm{CYP} 3 \mathrm{~A} 4^{2}$ & & $\begin{array}{l}\text { m- } \\
\text { chlorophenylpiperazine } \\
\text { (mCPP) }\end{array}$ & \\
\hline Vilazodone & $72^{3}$ & $96-99$ & $20-24$ & CYP3A4 ${ }^{2}$ & $\begin{array}{l}\text { CYP2C19, CYP2D6, } \\
\text { Carboxylesterase }\end{array}$ & & CYP2C8 (?) \\
\hline Vortioxetine & 75 & 98 & $57-66$ & CYP2D6 $^{2}$ & $\begin{array}{l}\text { CYP3A4, CYP2C19, } \\
\text { CYP2C9, CYP2A6, } \\
\text { CYP2C } 8, \text { CYP2B6 }\end{array}$ & & \\
\hline
\end{tabular}

CYP: Cytochrome P450; SNRI: Serotonin and noradrenaline reuptake inhibitor; SSRI: Selective serotonin reuptake inhibitor; TCA; tricyclic antidepressant; UGT: Uridine diphosphate glucuronosyltransferase.

${ }^{1}$ This refers to normal metabolism. Some subjects may not have this enzyme or the enzyme is inhibited. Other enzymes may become more important during induction.

${ }^{2}$ Any substrate competes with others for the corresponding enzyme and inhibits it (competitive inhibition). Data in the literature shows that competitive inhibition may occur at CYP1A2, CYP2C9, CYP2C19, CYP2D6, and CYP3A4. UGTs tend to have overlapping substrates and it is not clear that they can be subject to competitive inhibition. For example, venlafaxine can behave as a CYP2D6 competitive inhibitor.

${ }^{3}$ Absorption is decreased when not administered with food. 
Table 3. Summary of pharmacokinetic drug interactions between antiepileptics and antidepressants.

\begin{tabular}{|c|c|c|c|c|}
\hline Antiepileptic & Antidepressant & Effect & Proposed mechanism & References \\
\hline \multirow[t]{9}{*}{ Carbamazepine } & TCA & Decrease in plasma TCA concentrations $(40-70 \%)$ & $\begin{array}{l}\text { Induction of various CYP } \\
\text { isoforms (CYP2C19, } \\
\text { CYP1A2 and CYP3A4) }\end{array}$ & [34] \\
\hline & Fluoxetine & $\begin{array}{l}\text { Minimal increase or no change in plasma concentrations of } \\
\text { carbamazepine }\end{array}$ & Inhibition of CYP3A4 (?) & [89-91] \\
\hline & Paroxetine & Decrease by $25 \%$ in plasma concentrations of paroxetine & Induction of CYP (?) & {$[60,61]$} \\
\hline & Fluvoxamine & $\begin{array}{l}\text { Minimal increase or no change in plasma concentrations of } \\
\text { carbamazepine }\end{array}$ & Inhibition of CYP3A4 (?) & {$[91,96,97]$} \\
\hline & Sertraline & Marked decrease in plasma sertraline concentrations in two patients & Induction of CYP3A4 & [62] \\
\hline & Citalopram & $\begin{array}{l}\text { Decrease in plasma concentrations of S-citalopram and R-citalopram } \\
\text { by } 27 \text { and } 31 \%\end{array}$ & Induction of CYP3A4 & [63] \\
\hline & Milnacipran & Decrease by $20 \%$ in plasma concentrations of milnacipran & $\begin{array}{l}\text { Induction of CYP3A4 and } \\
\text { UGT }\end{array}$ & [64] \\
\hline & Mirtazapine & Reduction by $39 \%$ in $\mathrm{C}_{\max }$ of mirtazapine and by $66 \%$ in its AUC & Induction of CYP3A4 & [65] \\
\hline & Bupropion & Decrease in the $C_{\max }$ of bupropion by $87 \%$ and in its AUC by $90 \%$ & Induction of CYP3A4 & [67] \\
\hline Phenobarbital & TCAs & Decrease in plasma TCA concentrations $(40-70 \%)$ & $\begin{array}{l}\text { Induction of various CYP } \\
\text { isoforms (CYP2C19, } \\
\text { CYP1A2 and CYP3A4) }\end{array}$ & [34] \\
\hline \multirow[t]{4}{*}{ Phenytoin } & TCAs & Decrease in TCA plasma concentrations $(40-70 \%)$ & $\begin{array}{l}\text { Induction of various CYP } \\
\text { isoforms (CYP2C19, } \\
\text { CYP1A2 and CYP3A4) }\end{array}$ & [34] \\
\hline & Fluoxetine & Increase in plasma concentrations of phenytoin & Inhibition of CYP2C9 & [88] \\
\hline & Fluvoxamine & $\begin{array}{l}\text { A case report documented a 3-fold increase in serum concentrations of } \\
\text { phenytoin after administration of fluvoxamine }\end{array}$ & $\begin{array}{l}\text { Inhibition of both CYP2C9 } \\
\text { and CYP2C19 }\end{array}$ & {$[98]$} \\
\hline & Mirtazapine & Reduction by $33 \%$ in $\mathrm{C}_{\max }$ of mirtazapine and by $47 \%$ in its AUC & Induction of CYP3A4 & [66] \\
\hline \multirow[t]{4}{*}{ Valproic acid } & Amitriptyline & $\begin{array}{l}50 \% \text { to } 60 \% \text { elevation in plasma concentrations of amitriptyline and } \\
\text { nortriptyline }\end{array}$ & $\begin{array}{l}\text { Inhibition of CYP2C9 and, } \\
\text { possibly CYP2C19 and } \\
\text { CYP3A4 }\end{array}$ & {$[71-73,79]$} \\
\hline & Doxepin & $\begin{array}{l}\text { Higher serum concentrations of doxepin plus N-doxepin (by } 124 \% \text {, } \\
p<0.01 \text { ) in patients comedicated with valproic acid }\end{array}$ & $\begin{array}{l}\text { Inhibition of CYP2C9 and, } \\
\text { possibly CYP2C19 and } \\
\text { CYP3A4 }\end{array}$ & {$[80]$} \\
\hline & Fluoxetine & Increase in plasma concentrations of valproate & Inhibition of CYP2C9 & [92-94] \\
\hline & Venlafaxine & $\begin{array}{l}\text { Serum concentrations of the active metabolite } \mathrm{O}- \\
\text { desmethylvenlafaxine were significantly higher (by } 27 \%, \mathrm{p}<0.02) \text { in }\end{array}$ & Inhibition of CYP2C9 & [80] \\
\hline
\end{tabular}




\begin{tabular}{|l|l|l|l|c|}
\hline & & $\begin{array}{l}\text { patients treated with the combination of valproic acid with } \\
\text { venlafaxine. }\end{array}$ & $\begin{array}{l}\text { Lower serum concentrations of lamotrigine in patients comedicated } \\
\text { with fluoxetine }\end{array}$ & Induction of UGT enzymes? \\
\hline Lamotrigine & Fluoxetine & Slight increase (by 18\%) in plasma concentrations of lamotrigine & Inhibition of UGT2B7? \\
\hline & Sertraline & [103] \\
\hline
\end{tabular}

$\mathrm{C}_{\max }$ : Peak plasma concentration; AUC: Area under the plasma concentration-time curve; CYP: Cytochrome P450; TCA: tricyclic antidepressant. UGT: Uridine diphosphate glucuronosyltransferase. 
Table 4. Practical summary of antiepileptic and antidepressant drug interactions

\begin{tabular}{|c|c|c|c|}
\hline ANTIEPILEPTICS & ANTIDEPRESSANTS & OUTCOME & ACTIONS \\
\hline \multirow{7}{*}{$\begin{array}{l}\text { PK DI. Powerful inducers: } \\
\text { carbamazepine, phenobarbital } \\
\text { phenytoin, primidone }\end{array}$} & & \multirow{6}{*}{$\begin{array}{l}\downarrow \text { antidepressant level 2-4 wks after } \\
\quad \text { adding inducer } \\
\uparrow \text { antidepressant level 2-4 wks after D/C } \\
\text { Inducer }\end{array}$} & In the absence of TDM, use correction factor: ${ }^{1}$ \\
\hline & Bupropion $>^{2}$ & & $\begin{array}{l}\text { Better to avoid unless having extensive bupropion } \\
\text { TDM experience }\end{array}$ \\
\hline & \multirow{3}{*}{\begin{tabular}{|l|} 
Mirtazapine $>$ \\
TCAs $>^{2}$ \\
Citalopram, milnacipran, paroxetine
\end{tabular}} & & $2-3$ \\
\hline & & & $2(1.4-2,5)^{4}$ Better using TCA TDM \\
\hline & & & $\begin{array}{l}1.3 \text { If this correction factor is correct, it may not be } \\
\text { clinically relevant }\end{array}$ \\
\hline & $\begin{array}{l}\text { Agomelatine, desvenlafaxine, } \\
\text { duloxetine, escitalopram, } \\
\text { levomilnacipran, reboxetine, } \\
\text { sertraline, venlafaxine, vilazodone, } \\
\text { vortioxetine }\end{array}$ & & $\begin{array}{l}\text { Not studied } \\
\text { Be careful; induction of these antidepressants is } \\
\text { possible. Reboxetine and vilazodone (dependent on } \\
\text { CYP3A4 for their metabolism) may require high } \\
\text { correction factors: } \geq 5 \text { ) }\end{array}$ \\
\hline & Fluoxetine, fluvoxamine & Not relevant & Possibly no clinically relevant changes \\
\hline $\begin{array}{l}\text { PK DI. Mild CYP3A4 } \\
\text { inducers: }^{3} \\
\text { Clobazam, eslicarbazepine, } \\
\text { felbamate, oxcarbazepine, } \\
\text { topiramate, } \\
\text { Rufinamide }\end{array}$ & $\begin{array}{l}\text { Possibly relevant for: bupropion, } \\
\text { mirtazapine, TCAs, reboxetine, } \\
\text { vilazodone }\end{array}$ & $\begin{array}{l}\downarrow \text { mild antidepressant level 2-4 wks after } \\
\text { adding mild inducer } \\
\uparrow \text { mild antidepressant level 2-4 wks after } \\
\text { D/C mild inducer }\end{array}$ & $\begin{array}{l}\text { Monitor for } \downarrow \text { efficacy after adding mild inducer. } \\
\text { Monitor for ADRs after discontinuing mild inducer }\end{array}$ \\
\hline PK DI. Phenytoin, valproate & \multirow[t]{2}{*}{ Fluoxetine, fluvoxamine } & \multirow{2}{*}{$\begin{array}{l}\uparrow \text { antiepileptic level after adding inhibitor } \\
\downarrow \text { antiepileptic level after D/C inhibitor }\end{array}$} & \multirow{2}{*}{$\begin{array}{l}\text { Use antiepileptic TDM } \\
\text { It may be safer to select another antidepressant }\end{array}$} \\
\hline $\begin{array}{l}\text { Not studied but likely to be } \\
\text { relevant: clobazam, } \\
\text { lacosamide, phenobarbital, or } \\
\text { primidone. }\end{array}$ & & & \\
\hline $\begin{array}{l}\text { Not studied at steady state; } \\
\text { inhibitory effects of } \\
\text { fluoxetine: carbamazepine, } \\
\text { felbamate, tiagabine, } \\
\text { zonisamide }\end{array}$ & Fluoxetine & $\begin{array}{l}\uparrow \text { antiepileptic level } 2-3 \text { months after } \\
\text { adding fluoxetine in average patient (some } \\
\text { may take longer) } \\
\downarrow \text { antiepileptic level } 2-3 \text { months after } \\
\text { adding fluoxetine in average patient (some } \\
\text { may take longer) }\end{array}$ & $\begin{array}{l}\text { Use antiepileptic TDM } \\
\text { It may be safer to select another antidepressant }\end{array}$ \\
\hline PK DI. Valproate & TCAs & $\begin{array}{l}\uparrow \text { TCA level after adding valproate } \\
\downarrow \text { TCA level after D/C valproate } \\
\end{array}$ & $\begin{array}{l}\text { Better using TCA TDM } \\
\text { Monitor for TCA ADRs }\end{array}$ \\
\hline PK DI. Lamotrigine & Fluoxetine, sertraline & $\begin{array}{l}\text { Some isolated cases suggest that } \\
\text { lamotrigine induction may be possible with } \\
\text { fluoxetine and lamotrigine inhibition may }\end{array}$ & $\begin{array}{l}\text { Be alert to the possibility that fluoxetine may } \downarrow \\
\text { lamotrigine levels while sertraline may } \uparrow \\
\text { lamotrigine level }\end{array}$ \\
\hline
\end{tabular}




\begin{tabular}{|c|c|c|c|}
\hline & & be possible with sertraline. & $\begin{array}{l}\text { Consider lamotrigine TDM before and after adding } \\
\text { fluoxetine or sertraline or select another } \\
\text { antidepressant }\end{array}$ \\
\hline PD DI. Pregabalin & Antidepressants & $\begin{array}{l}\text { May have additive effects for generalized } \\
\text { anxiety disorder (not well-studied) }\end{array}$ & Be aware \\
\hline $\begin{array}{l}\text { PD DI. Carbamazepine, } \\
\text { gabapentin, oxcarbazepine, } \\
\text { pregabalin }\end{array}$ & SNRIs, TCAs & $\begin{array}{l}\text { May have additive effects for pain treatment } \\
\text { (not well-studied) }\end{array}$ & Be aware \\
\hline $\begin{array}{l}\text { PD DI. Topiramate, valproic } \\
\text { acid }\end{array}$ & $\begin{array}{l}\text { TCAs, particularly amitriptyline. } \\
\text { Possibly venlafaxine }\end{array}$ & $\begin{array}{l}\text { May have additive effects for migraine } \\
\text { treatment (not well-studied) }\end{array}$ & $\begin{array}{l}\text { Be aware } \\
\text { Remember that valproic acid may } \uparrow \text { TCA level }\end{array}$ \\
\hline $\begin{array}{l}\text { PD DI. Zonisamide (possibly } \\
\text { topiramate) }\end{array}$ & Bupropion & $\begin{array}{l}\text { May have additive effects for weight } \\
\text { reduction (not well-studied) }\end{array}$ & Be aware \\
\hline PD DI. Gabapentin & SNRIs, SSRIs & $\begin{array}{l}\text { May have additive effects for reducing } \\
\text { menopausal symptoms (not well-studied; } \\
\text { none of these drugs have been approved) }\end{array}$ & Be aware \\
\hline $\begin{array}{l}\text { PD DI. Phenobarbital, } \\
\text { primidone, topiramate, } \\
\text { vigabatrin }>\text { zonisamide }> \\
\text { felbamate, levetiracetam, } \\
\text { tiagabine }\end{array}$ & Antidepressants & $\begin{array}{l}\text { These antiepileptics have been associated } \\
\text { with depression }\end{array}$ & $\begin{array}{l}\text { Avoid using them in patients taking antidepressants } \\
\text { for depression } \\
\text { If you use them, review PK DIs }\end{array}$ \\
\hline $\begin{array}{l}\text { PD DI. Antiepileptics for } \\
\text { epilepsy }\end{array}$ & Bupropion, TCAs & $\begin{array}{l}\text { These antidepressants have been associated } \\
\text { with } \uparrow \text { risk for seizures }\end{array}$ & $\begin{array}{l}\text { Avoid using them in patients taking antiepileptics } \\
\text { for epilepsy } \\
\text { If you use them, review PK DIs }\end{array}$ \\
\hline $\begin{array}{l}\text { PD DI. Antiepileptics for } \\
\text { epilepsy }\end{array}$ & $\begin{array}{l}\text { Fluoxetine (possible other SSRIs and } \\
\text { SNRIs) }\end{array}$ & $\begin{array}{l}\text { Fluoxetine has displayed in vitro } \\
\text { antiepileptic properties in some models } \\
\text { Other SSRIs and SNRIs have been } \\
\text { associated with } \downarrow \text { risk for seizures in meta- } \\
\text { analyses but there are also case reports } \\
\text { associating them with seizures in patients } \\
\text { with no seizure history }\end{array}$ & $\begin{array}{l}\text { Consider them when needing antidepressant in } \\
\text { patients taking antiepileptics for not-well-controlled } \\
\text { epilepsy } \\
\text { If you decide to use fluoxetine, be very careful with } \\
\text { PK DIs }\end{array}$ \\
\hline $\begin{array}{l}\text { PD DI. Topiramate, } \\
\text { zonisamide }\end{array}$ & Amitriptyline, mirtazapine, paroxetine & $\begin{array}{l}\text { These antiepileptics have been associated } \\
\text { with } \downarrow \text { weight gain }\end{array}$ & $\begin{array}{l}\text { Be aware } \\
\text { If you use them, review other PK and PD DIs }\end{array}$ \\
\hline PD DI. Rufinamide & SSRIs & $\begin{array}{l}\text { Rufinamide has been associated with } \downarrow \text { in } \\
\text { QTc }\end{array}$ & $\begin{array}{l}\text { Be aware } \\
\text { If you use them, review other PK and PD DIs }\end{array}$ \\
\hline PD DI. Most antiepileptics & Mirtazapine, TCAs, and trazodone & Additive sedation risk & $\begin{array}{l}\text { Be aware } \\
\text { Remember that felbamate, lacosamide, lamotrigine } \\
\text { and tiagabine are less sedating }\end{array}$ \\
\hline $\begin{array}{l}\text { PD DI. Carbamazepine, } \\
\text { gabapentin, pregabalin, } \\
\text { retigabine, valproate }\end{array}$ & Amitriptyline, mirtazapine, paroxetine & $\begin{array}{l}\text { These antiepileptics and antidepressants } \\
\text { have been associated with } \uparrow \text { weight gain and } \\
\text { may have additive effects. }\end{array}$ & Be aware \\
\hline PD DI. Carbamazepine, & Mirtazapine & These antiepileptics and mirtazapine have & Be aware \\
\hline
\end{tabular}




\begin{tabular}{|c|c|c|c|}
\hline $\begin{array}{l}\text { phenobarbital, phenytoin, } \\
\text { primidone }\end{array}$ & & $\begin{array}{l}\text { been associated with hyperlipidemia and } \\
\text { may have additive effects }\end{array}$ & If you use them, review other PK and PD DIs \\
\hline PD DI. Most antiepileptics & SNRIs, SSRIs & $\begin{array}{l}\text { Most antiepileptics and these } \\
\text { antidepressants have been associated with } \\
\text { nausea/vomiting and may have additive } \\
\text { effects }\end{array}$ & $\begin{array}{l}\text { Be aware } \\
\text { If you use them, review other PK and PD DIs } \\
\text { Mirtazapine and TCAs may have less risk for } \\
\text { nausea and may have anti-nausea effects in some } \\
\text { patients }\end{array}$ \\
\hline PD DI. Retigabine & $\begin{array}{l}\text { Most TCAs }>^{2} \text { mirtazapine, paroxetine } \\
\text { due to antimuscarinic activity; } \\
\text { SNRIs and reboxetine probably due to } \\
\text { noradrenergic mechanisms }\end{array}$ & $\begin{array}{l}\text { Retigabine and these antidepressants have } \\
\text { been associated with } \uparrow \text { risk for urinary } \\
\text { retention }\end{array}$ & Be aware if you combine them \\
\hline $\begin{array}{l}\text { PD DI. Oxcarbazepine }>^{2} \\
\text { carbamazepine }\end{array}$ & Probably all antidepressants & $\begin{array}{l}\text { Oxcarbazepine and carbamazepine and } \\
\text { antidepressants have been associated with } \uparrow \\
\text { risk for hyponatremia }\end{array}$ & $\begin{array}{l}\text { Be particularly careful in geriatric females who } \\
\text { have more risk of developing hyponatremia. } \\
\text { Polydipsic patients with severe mental illness may } \\
\text { have hyponatremia risk with only one of these } \\
\text { drugs }\end{array}$ \\
\hline PD DI. Felbamate, retigabine & $\begin{array}{l}\text { SSRIs (particularly citalopram, } \\
\text { fluoxetine and sertraline) }\end{array}$ & Possible additive risk for $\uparrow$ QTc & $\begin{array}{l}\text { Be vigilant (can be lethal) } \\
\text { Consider need for ECG } \\
\text { Torsades de pointes is very rare but additive risk } \\
\text { factors are family history of sudden death; personal } \\
\text { history of syncopes, arrhythmias or heart cond- } \\
\text { itions; hypokalemia, hypomagnesemia, and co- } \\
\text { prescription of other medications that } \uparrow \text { QTc. Cases } \\
\text { are more frequent in females aged }>65 \text { years } \\
\text { In the US, consider legal risk. The FDA requires a } \\
\text { QTc warning for the use of high doses of } \\
\text { citalopram } \\
\text { Consider these warnings when co-prescribing }\end{array}$ \\
\hline $\begin{array}{l}\text { PD DI. Carbamazepine, } \\
\text { felbamate, phenytoin, } \\
\text { valproate }\end{array}$ & Agomelatine & Possible additive risk for hepatic injury & $\begin{array}{l}\text { Be extremely careful when adding agomelatine to } \\
\text { these antiepileptics and consider other } \\
\text { antidepressants }\end{array}$ \\
\hline $\begin{array}{l}\text { PD DI. Carbamazepine, } \\
\text { felbamate, phenytoin, } \\
\text { valproate }\end{array}$ & $\begin{array}{l}\text { Bupropion, duloxetine, TCAs and } \\
\text { trazodone }\end{array}$ & Possible additive risk for hepatic injury & $\begin{array}{l}\text { Be very careful when adding these antidepressants } \\
\text { and antiepileptics; consider other alternatives and } \\
\text { monitor liver enzymes } \\
\text { These antidepressants should not be used in those } \\
\text { with prior history of liver injury secondary to } \\
\text { antiepileptics, or with current liver enzyme } \\
\text { elevations during antiepileptic treatment }\end{array}$ \\
\hline PD DI. Valproate & SSRIs & Possible additive hemorrhagic risk & Monitor closely if you decide to co-prescribe \\
\hline $\begin{array}{l}\text { PD DI. Topiramate, } \\
\text { zonisamide rarely }\end{array}$ & $\begin{array}{l}\text { TCAs and mirtazapine due to } \\
\text { antimuscarinic activity }\end{array}$ & Both may be associated with heat stroke & $\begin{array}{l}\text { In elderly and/or exposed to strenuous exercise or } \\
\text { high temperatures: }\end{array}$ \\
\hline
\end{tabular}




\begin{tabular}{|l|l|l|l|}
\hline & & & $\begin{array}{l}\text { Be vigilant (can be lethal). Encourage proper } \\
\text { hydration }\end{array}$ \\
\hline $\begin{array}{l}\text { PD DI. Carbamazepine, } \\
\text { phenobarbital, phenytoin, } \\
\text { primidone }>^{2} \text { oxcarbazepine, } \\
\text { topiramate, valproate }\end{array}$ & SSRIs & Possible additive osteoporosis risk & Monitor closely if you decide to co-prescribe \\
\hline
\end{tabular}

ADR: adverse drug reaction; PD DI: pharmacodynamic drug interaction; PK DI: pharmacokinetic drug interaction; SNRI: Serotonin and noradrenaline reuptake inhibitor; SSRI Selective serotonin reuptake inhibitor.

'Reviewed PK DI studies were used to estimate correction factors, which are $>1$ in inducers and $<1$ in inhibitors. A correction factor of 2 indicates that you need to double the dose for the same effect. A correction factor of 0.5 indicates that you need to halve the dose for the same effect. The further the correction factor is from 1 , the more relevant the DI may be. The therapeutic window or index also determines the clinical relevance of correction factors.

${ }^{2}$ Drugs preceding $">$ " will produce a more powerful outcome than the drugs listed on the following line.

${ }^{3}$ The bupropion correction factor is 10 . It is so large that it appears better to avoid bupropion unless TDM is available.

${ }^{4}$ The correction factor of 2 for TCAs is based on a decrease of $50 \%$ of plasma concentrations. As Table 3 shows, the decreases may range from $40 \%$ to $70 \%$; this will provide a correction factor ranging from 2.5 to 1.4. It is better to use TDM than correction factors to correct the dose in each patient more accurately. 


\section{PHARMACOKINETICS OF ANTIEPILEPTICS FOR ENDOGENOUS COMPOUNDS INFLUENCING SAFETY}

OSTEOPOROSIS (after many years of treatment, making it difficult to establish frequencies)

Induction of Vitamin D metabolism

Carbamazepine, phenobarbital, phenytoin, primidone $>^{1}$ oxcarbazepine, topiramate, valproate

THYROID DISTURBANCES (relatively uncommon)
Induction of thyroid hormone metabolism
Carbamazepine, phenytoin ${ }^{2}$

Figure 1. Pharmacokinetics of antiepileptics for endogenous compounds influencing safety.

${ }^{1}$ Drugs preceding ">" will produce this ADR more frequently than drugs following ">".

${ }^{2}$ Oxcarbazepine may be associated with mild thyroid disturbances.

${ }^{3}$ Valproate appears to decrease total and high-density lipoprotein (HDL) cholesterol by unknown mechanisms.

${ }^{4}$ Carbamazepine, phenobarbital and phenytoin may be associated with $\uparrow$ increases in serum sex hormone-binding globulin concentrations in both men and women. Over time, the $\uparrow$ increase in serum sex hormone-binding globulin levels leads to $\downarrow$ testosterone and estradiol activity, which may result in diminished potency in men and menstrual disorders in some women. Valproic acid medication may have effects on serum androgen concentrations and it $\downarrow$ reduces serum follicle stimulating hormone levels in men; clinical relevance is unknown. In fertile women with epilepsy, there is more agreement that valproic acid may have clinical relevance and be associated with polycystic changes in the ovaries, high serum testosterone concentrations (hyperandrogenism) and menstrual disorders. These disorders are especially common among epileptic women who have gained weight during valproic acid treatment. It is not established whether these changes occur in non-epileptic women taking valproic acid for years.

${ }^{5}$ Other abnormalities associated with folic acid deficits are gingival overgrowth associated with phenytoin treatment and poor oral hygiene, and macrocytic anemia associated with phenytoin and phenobarbital. It is believed that phenytoin may inhibit the folic acid transporter. 


\section{PHARMACODYNAMICS FOR ANTIEPILEPTIC EFFICACY}

ANTIEPILEPTIC ACTIVITY ${ }^{1}$

$\downarrow$ Activity of voltage-dependent sodium channels

Carbamazepine, eslicarbazepine, felbamate, lacosamide, lamotrigine, oxcarbazepine, phenytoin, rufinamide, topiramate, zonisamide

$\downarrow$ Activity of voltage-dependent calcium channels

Ethosuximide, gabapentin, lamotrigine, pregabalin, topiramate, zonisamide

$\uparrow \boldsymbol{G A B A}$ neurotransmission

Clobazam, felbamate, gabapentin, phenobarbital, pregabalin, primidone, stiripentol, tiagabine, topiramate, vigabatrin

Complex including $\uparrow \boldsymbol{G A B A}$ neurotransmission

Valproate

$\downarrow$ Glutamatergic neurotransmission

Felbamate, topiramate

Complex: binds to synaptic vesicle protein $2 A$ ( $\downarrow$ synaptic vesicle recycling and $N T$ release)

Levetiracetam

Allosteric modulator which enhances the activity of the slow voltage-gated potassium channels Retigabine

MOOD STABILIZER ACTIVITY ${ }^{2}$

At intracellular signaling system (inositol signaling)

Carbamazepine, valproate

Unknown mechanism

Lamotrigine

ANXIOLYTIC ACTIVITY

$\uparrow \boldsymbol{G A B A}$ neurotransmission

Clobazam, pregabalin (off-label in the US) ${ }^{3}$

\section{FOR PAIN ${ }^{4}$}

$\downarrow$ Activity of voltage-dependent sodium or calcium channels

Carbamazepine, gabapentin, oxcarbazepine, pregabalin

\begin{tabular}{c} 
FOR MIGRAINE PROPHYLAXIS \\
Unknown mechanism \\
Topiramate, valproate \\
\hline$\downarrow$ APPETITE AND WEGHT LOSS (off-label in the US) \\
Inhibition of carbonic anhydrase \\
Topiramate, zonisamide \\
\hline MENOPAUSAL VASOMOTOR SYMPTOMS (HOT FLASHES \& NIGHT SWEATS) \\
Unknown mechanism \\
Gabapentin (off-label in the US)
\end{tabular}

Figure 2. Pharmacodynamics for antiepileptic efficacy.

This figure is an update from Figure 2 in a prior article [28].

${ }^{1}$ Different articles describe different mechanisms of action for some drugs including levetiracetam, valproate and zonisamide.

${ }^{2}$ Antiepileptics approved in the US for bipolar disorder include: i) valproate for mania; ii)

carbamazepine for the treatment of acute manic and mixed episodes of bipolar disorder; and iii)

lamotrigine for prophylaxis, particularly of depressive phases. Treatment guidelines also consider:

i) valproate monotherapy or adjunctive therapy for bipolar depression or prophylaxis, ii)

carbamazepine monotherapy or adjunctive therapy for prophylaxis, and iii) lamotrigine

monotherapy or adjunctive therapy for bipolar depression. Gabapentin, lamotrigine and topiramate

mania RCTs were negative. Oxcarbazepine bipolar disorder RCTs appear promising. There are no published RCTs for eslicarbazepine, levetiracetam or zonisamide.

${ }^{3}$ Pregabalin is approved for generalized anxiety disorder in Europe but not in the US. Clobazam has not been approved for anxiety in the US but has been widely used as an anxiolytic in other countries. Other antiepileptics may have antianxiety properties. 
${ }^{4}$ In the US approved drugs include: i) carbamazepine for trigeminal neuralgia, ii) gabapentin for postherpetic neuralgia, and iii) pregabalin for postherpetic neuralgia and diabetic neuropathic pain. Lacosamide is being studied in RCTs for diabetic neuropathic pain. Oxcarbazepine is usually considered an alternative for trigeminal neuralgia when patients cannot tolerate carbamazepine. Other antiepileptics, including levetiracetam, lamotrigine and phenytoin are considered by some authors as acceptable treatments for neuropathic pain.

${ }^{5}$ In the US, the only antiepileptics approved for migraine prophylaxis are topiramate and valproate. ${ }^{6}$ Topiramate and zonisamide treatments are frequently associated with weight loss. In the US, the combination of topiramate and phentermine (a sympathomimetic amine anorectic agent) has been approved as an adjunctive treatment to a reduced-calorie diet and increased physical activity for chronic weight management in obesity or overweight with complications.

NT; neurotransmitter; RTC: randomized clinical trial. 
PHARMACODYNAMICS FOR ANTIEPILEPTIC SAFETY

$$
\text { SEDATION (common) }
$$

Same mechanism that explains antiepileptic efficacy

FGAED and topiramate $>^{1}$ other SGAEDs $>^{1}$ felbamate, lacosamide, lamotrigine, tiagabine

COGNITIVE IMPAIRMENT(common)

Same mechanism that explains antiepileptic efficacy

Definitively in FGAEDs and probably in SGAEDs ${ }^{2}$

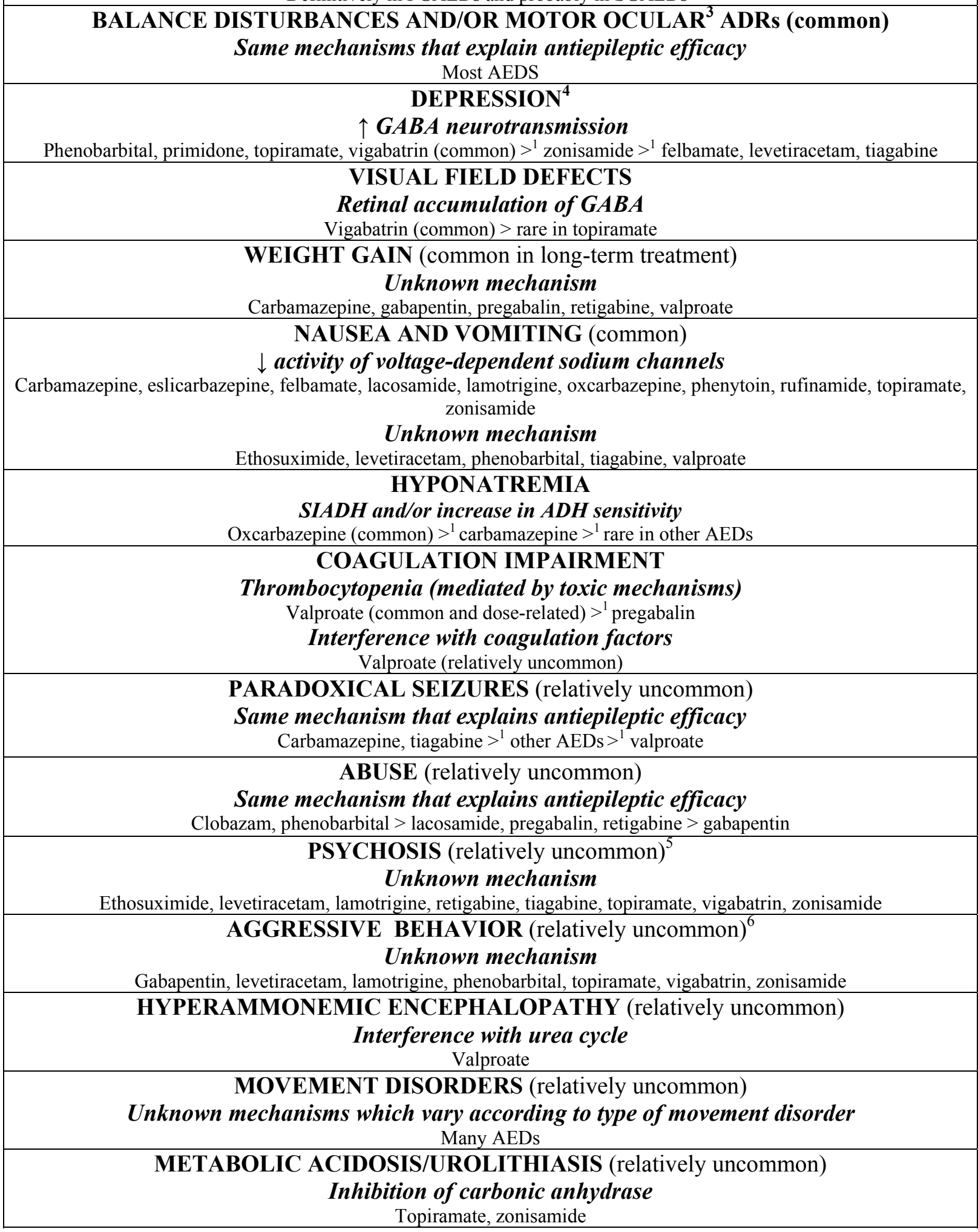




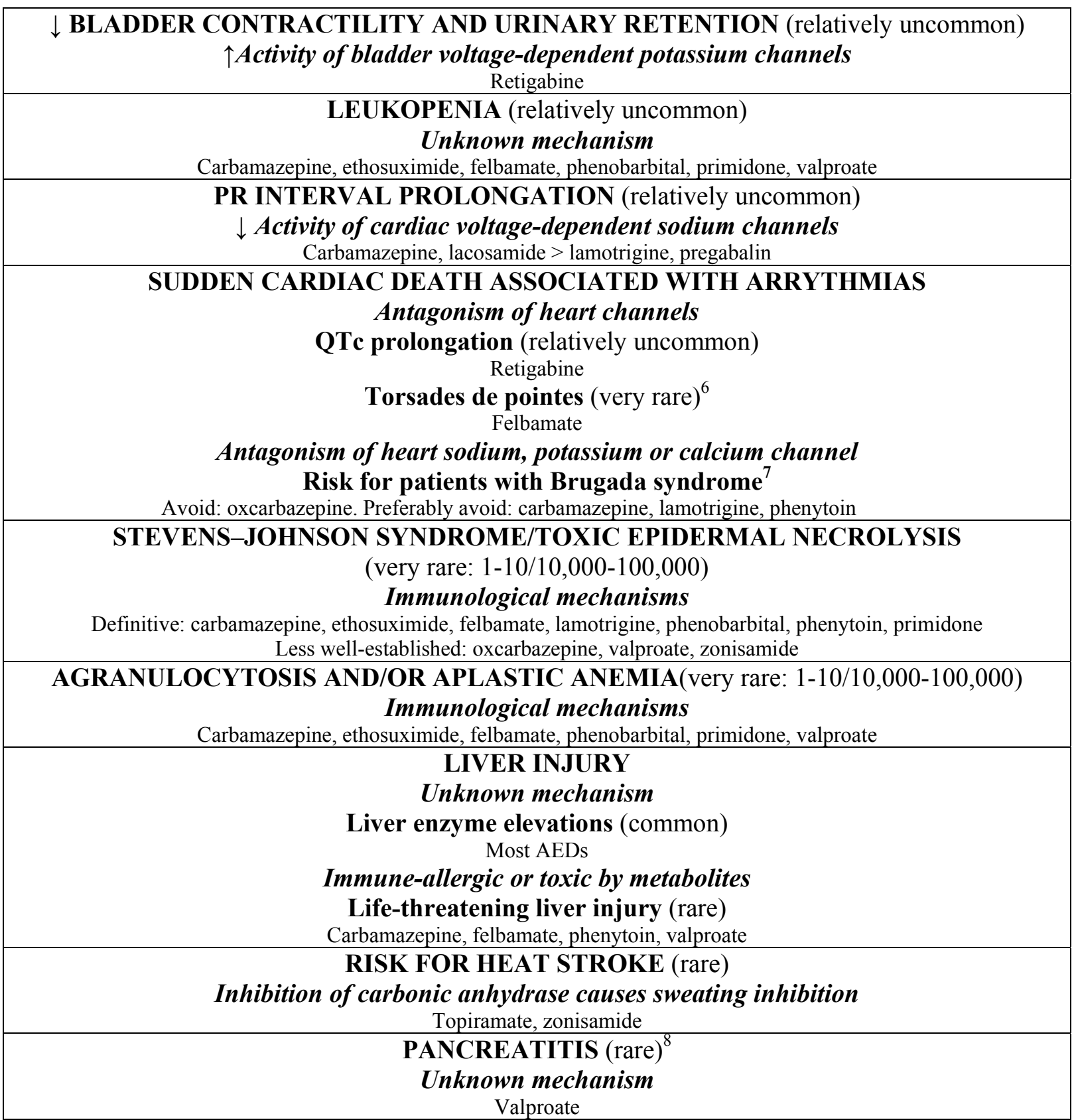

Figure 3. Pharmacodynamics for antiepileptic safety.

This figure is an update from Figure 3 in a prior article [28].

${ }^{1}$ Drugs preceding " $>$ " will produce this ADR more frequently than drugs following ">".

${ }^{2}$ FGAEDs are associated with cognitive impairment in studies using neuropsychological testing.

There are few neuropsychological studies on SGAEDs. Various authors agree that phenobarbital has the worst cognitive profile among FGAEDs, and topiramate among SGAEDs, but disagree on the relative impairment associated with specific compounds and how topiramate compares with FGAEDs.

${ }^{3}$ They include diplopia and nistagmus.

${ }^{4}$ Different reviews describe different frequencies for each AED-induced depression. A comprehensive review described frequencies $>10 \%$ for phenobarbital, primidone, topiramate and vigabatrin; $7 \%$ for zonisamide in high doses; $\leq 4 \%$ for felbamate, levetiracetam and tiagabine; and $<1 \%$ for the rest of the studied AEDs. On the other hand, carbamazepine, lamotrigine, oxcarbazepine and valproate may have antidepressant properties in patients with epilepsy. 
${ }^{5}$ It is difficult to assess when the psychosis is really an AED ADR rather than a manifestation of the underlying or associated illnesses. Studies using lamotrigine and topiramate in bipolar disorder do not describe increased psychotic symptoms.

${ }^{6}$ It is difficult to assess when aggressive behavior is really an AED ADR rather than an underlying or associated illness.

${ }^{6}$ There is general agreement in the literature that most drugs that cause torsade de pointes can be identified by assessing whether they block the human ether à gogo related gene (hERG) potassium channel and prolong the QT interval on the electrocardiogram, but it is not well understood why some drugs that block this channel do not cause torsades de pointes. Johannesen et al. [144] have proposed that drugs that at the same concentration that block the inward calcium or sodium channels they offset the pro-torsade effect of blocking the outward hERG potassium channels.

${ }^{7}$ Brugada syndrome is identified by a specific ECG pattern (pseudo right bundle branch block and persistent ST elevation in leads V1 to V3) and high incidence of ventricular fibrillation in the absence of structural heart disease. Brugada syndrome is a channelopathy explained by genetic abnormalities in the cardiac sodium, potassium or calcium channels.

${ }^{8}$ The literature describes valproate-induced pancreatitis as very rare. A comprehensive review in Germany indicated that milder cases are much more common than the literature suggests. Pancreatitis may be particularly frequent in facilities for adults with intellectual disabilities. ADR: adverse drug reaction; AED: antiepileptic drug; common: ADR $\geq 10 \%$ in RCT; FGAED: first-generation antiepileptic drug; RTC: randomized clinical trial; SGAED: second-generation antiepileptic drug; SIADH: syndrome of inappropriate antidiuretic hormone. 


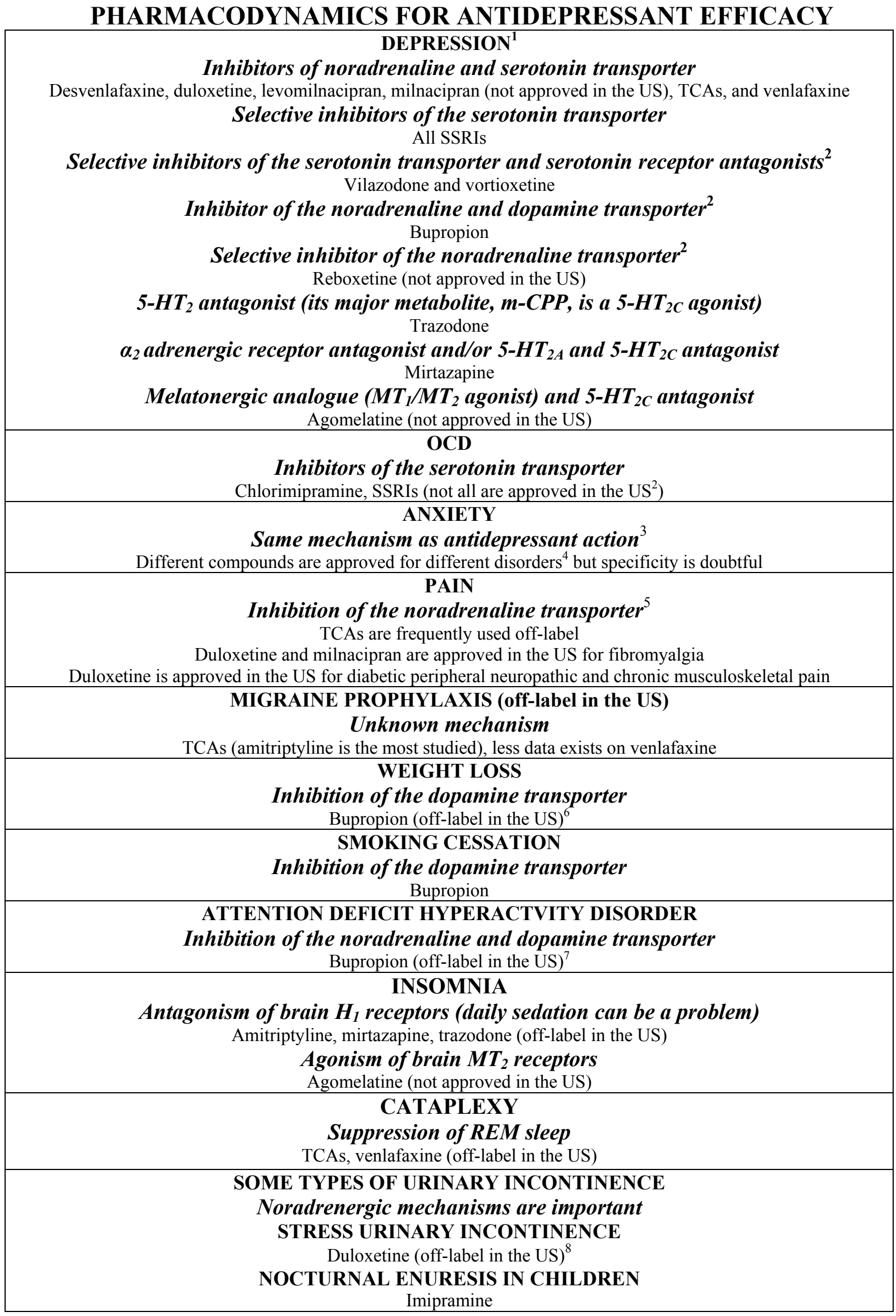


MENOPAUSAL VASOMOTOR SYMPTOMS (HOT FLASHES \& NIGHT SWEATS)

SNRIs, SSRIs (off-label in the US)

Unknown mechanism

Figure 4. Pharmacodynamics of efficacy for newer antidepressants. This figure is an update from Figure 1 in a prior article [33].

${ }^{\mathbf{1}}$ Textbooks usually report that the majority of antidepressants act by inhibiting reuptake transporters, but they also usually acknowledge that this is not a definitively proven theory, since the chronology of reuptake inhibition does not match the chronology of antidepressant response.

${ }^{2}$ Vilazadone is described as a dual-acting serotonergic antidepressant that combines selective 5-HT reuptake inhibition with partial agonism of the 5- $\mathrm{HT}_{1 \mathrm{~A}}$ receptor. Vortioxetine is described as combining 5-HT reuptake inhibition with $5-\mathrm{HT}_{3 \mathrm{~A}}$ and $5-\mathrm{HT}_{7}$ receptor antagonism, $5-\mathrm{HT}_{1 \mathrm{~B}}$ receptor partial agonism, $5-\mathrm{HT}_{1 \mathrm{~A}}$ receptor agonism.

${ }^{3}$ There are few attempts to describe the antidepressant pharmacological mechanism in anxiety disorders; the literature usually assumes that the various antidepressants work in anxiety using the same mechanism as in depression.

${ }^{4}$ Fluoxetine, fluvoxamine, paroxetine and sertraline are approved in the US for OCD. SNRIs such as duloxetine, desvenlafaxine and venlafaxine are used off-label.

${ }^{4}$ Duloxetine, escitalopram, paroxetine, and venlafaxine are approved for generalized anxiety in the US. Paroxetine, sertraline and venlafaxine are approved for social anxiety in the US. Paroxetine, sertraline and venlafaxine are approved for panic disorders in the US. TCAs are considered an effective off-label indication for panic disorder. A meta-analysis described the following newer antidepressants as significantly superior to placebo for panic disorder patients with the following increasing order of effectiveness: citalopram, sertraline, paroxetine, fluoxetine, and venlafaxine for panic symptoms and paroxetine, fluoxetine, fluvoxamine, citalopram, venlafaxine, and mirtazapine for overall anxiety symptoms. Aside from reboxetine and fluvoxamine, all drugs were associated with significantly lower dropout rates as compared with placebo. Based on a few agomelatine RCTs and uncontrolled studies, agomelatonine was considered a promising option when other pharmacological treatments had failed in anxiety disorders. Vortioxetine has had inconsistent results in generalized anxiety disorder RCTs.

${ }^{5}$ It is believed that for pain treatment the inhibition of the norepinephrine transporter may be more important than the inhibition of the serotonin transporter. There are antidepressant RCTs in pain syndromes for fibromyalgia, painful diabetic neuropathy, postherpetic neuralgia, and neuropathic pain (or painful neuropathy). Although venlafaxine is not approved in the US for pain, some RCTs support its use. The benefits of duloxetine and milnacipran over placebo in fibromyalgia are small.

${ }^{6} \mathrm{~A}$ meta-analysis indicated that weight loss with fluoxetine appears to be limited to the acute phase of treatment. The combination bupropion-naltrexone is being studied in RCTs for weight loss.

${ }^{7}$ According to a meta-analysis, bupropion is superior to placebo and effective in adults. There is very limited data on other antidepressants.

${ }^{8}$ Duloxetine can significantly improve the quality of life of patients with stress urinary incontinence, but it is unclear whether or not benefits are sustainable.

5-HT: Serotonin receptor; $\alpha$ : Alpha adrenergic receptor; H: Histamine receptor; MT: Melatonin receptors; OCD: Obsessive-compulsive disorder; RCT: Randomized clinical trial; TCA: tricyclic antidepressant; SNRI: Serotonin and noradrenaline reuptake inhibitor; SSRI: Selective serotonin reuptake inhibitor. 


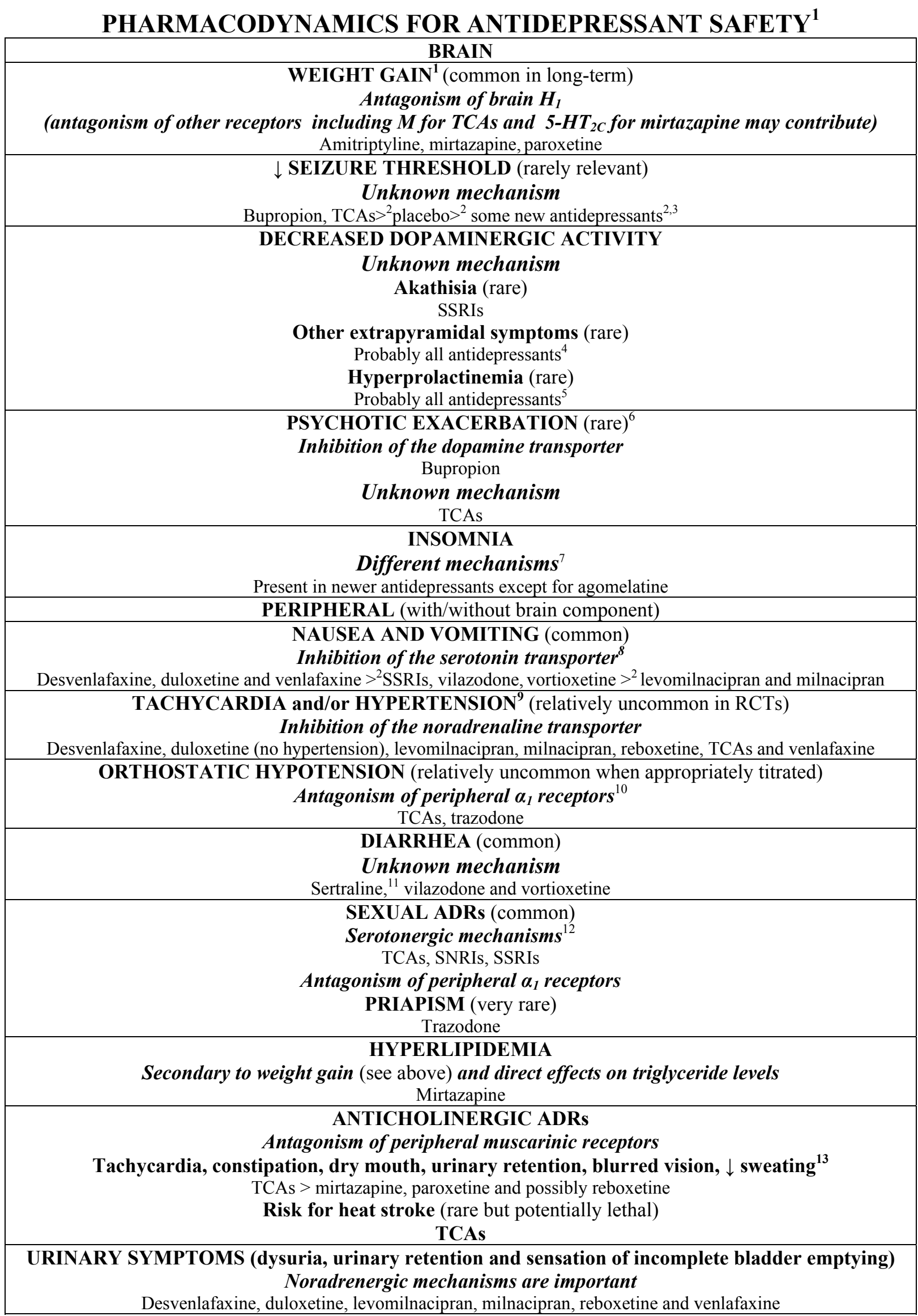




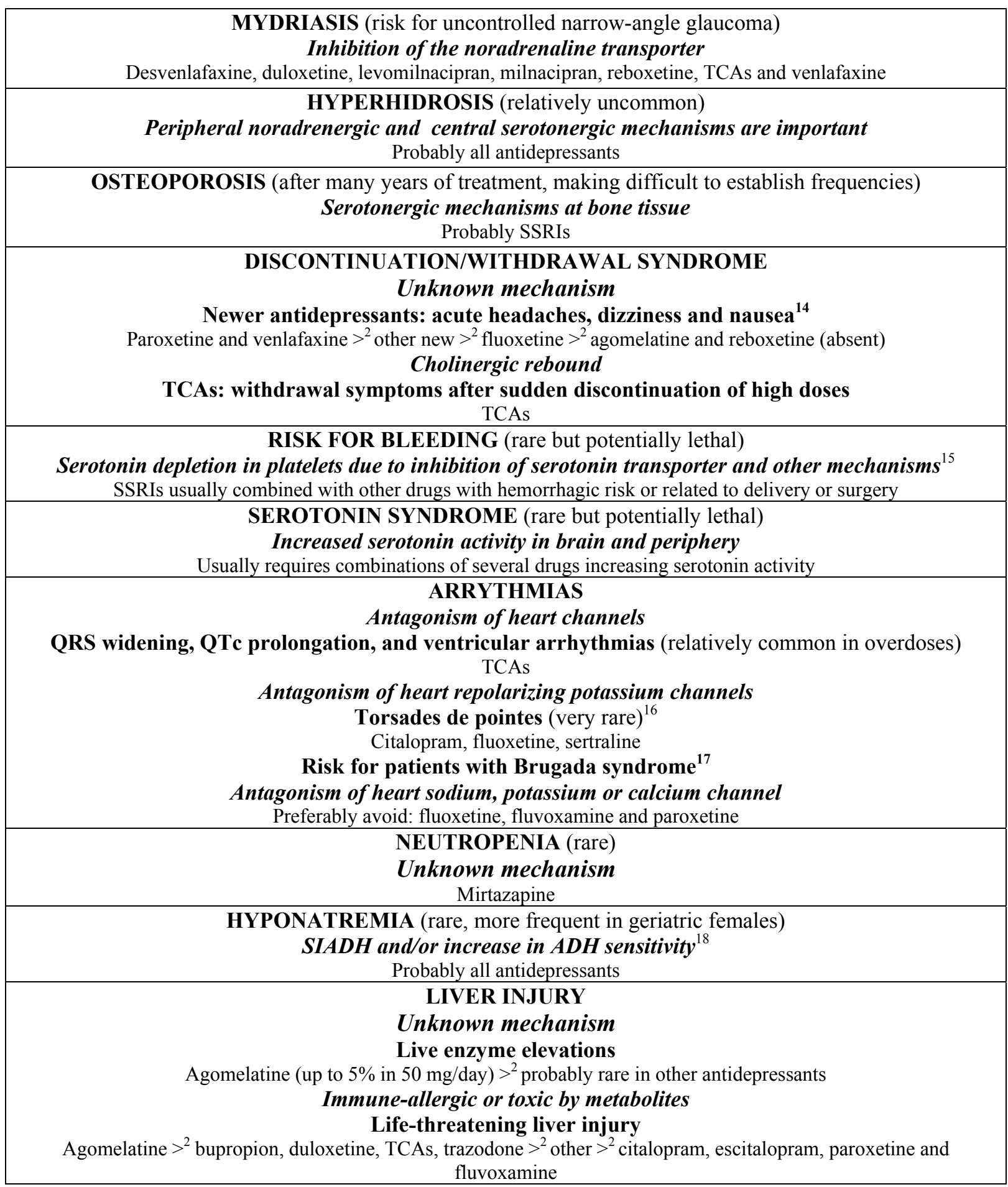

Figure 5. Pharmacodynamics of safety antidepressants.

This figure is an update from Figure 2 in a prior article [33].

${ }^{1}$ The more comprehensive review comparing antidepressant safety and meta-analysis of RCTs did not include more recently marketed compounds. Agomelatine is a 5-HT2 $2_{\mathrm{C}}$ antagonist. Insufficient data is available on long-term treatment to rule it out as a cause of weight gain. Case reports indicated some patients may gain significant weight with agomelatine long-term treatment. ${ }^{2}$ Drugs preceding ">" will produce this ADR more frequently than drugs following ">".

${ }^{3} \mathrm{~A}$ comprehensive literature review described bupropion as the only newer antidepressant associated with increased seizure risk in RCTs. 
${ }^{4}$ Extrapyramidal symptoms have been reported with different classes of antidepressants, are not dose-related, and can develop with short-term or long-term use.

${ }^{5}$ Symptomatic hyperprolactinemia has been reported with nearly all antidepressants. Incidence rates are not clearly established and symptoms were very rare.

${ }^{6}$ The literature is somewhat contradictory but, in selected cases, bupropion and TCAs appear to be associated with the induction of psychotic symptoms, in addition to the precipitation or worsening of an existing psychotic syndrome.

${ }^{7}$ Proposed mechanisms: 1) SSRIs may cause insomnia by 5- $\mathrm{HT}_{2}$ stimulation; 2) SNRIs and reboxetine may cause insomnia by blocking the noradrenaline transporter; and 3) mirtazapine may have a reverse-dose response effect with sedation at lower doses and with insomnia at higher doses. $\mathrm{H}_{1}$ antagonism is predominant at lower doses, while increased noradrenergic activity is predominant at higher doses.

${ }^{8}$ Nausea and vomiting are the most frequent causes of discontinuation of newer antidepressants during the first 30 days of treatment. They are $10 \%$ more frequent in venlafaxine than in SSRIs.

There are no comparisons of vilazodone and vortioxetine with other newer antidepressants. The estimate of the frequency of nausea is a rough estimate based on placebo-controlled RCTs. Mirtazapine and TCAs may help with some types of nausea.

${ }^{9}$ In a comprehensive review comparing newer antidepressant safety, venlafaxine was significantly associated with hypertension when compared with other newer antidepressants. Desvenlafaxine and milnacipran also appear to cause hypertension. Duloxetine has not been consistently associated with hypertension; increases in blood pressure have been mild, but caution should be used in patients with hypertension. Epidemiological studies have associated TCAs with hypertension.

${ }^{10}$ Mirtazapine has very low affinity for $\alpha_{1}$ receptors and has rarely been associated with syncopes. Venlafaxine has no affinity for $\alpha_{1}$ receptors but has been consistently associated with orthostatic hypotension in geriatric patients.

${ }^{11}$ Comprehensive reviews and meta-analyses agree that sertraline is associated with more diarrhea risk than other newer antidepressants.

${ }^{12}$ It has been proposed that sexual ADRS may be related to serotonergic stimulation of 5- $\mathrm{HT}_{2}$ and 5$\mathrm{HT}_{3}$ receptors, but their origin is complex, probably also involving the effect of 5-HT on nitric oxide production as well as other systems. Bupropion and mirtazapine may be no different than placebo. Agomelatine and reboxetine are probably associated with very low risk for sexual ADRs. Vilazodone appears to have low risk for sexual ADRs but is associated with more sexual ADRs than placebo.

${ }^{13}$ Amitriptyline, clomipramine, doxepin, imipramine, nortriptyline, protriptyline, and trimipramine have definitive antimuscarinic activity. Amoxapine, desimipramine, maprotiline, mirtazapine and paroxetine have low antimuscarinic activity. Citalopram, escitalopram, fluoxetine, trazodone and sertraline show antimuscarinic activity in some studies but not in all. Reboxetine frequently causes dry mouth and constipation, and more rarely urinary retention. It has been proposed that the noradrenergic mechanism may explain these antimuscarinic symptoms because 1) reboxetine's affinity for muscarinic receptors is too low to be relevant at therapeutic doses, and 2) no metabolites with greater antimuscarinic activity have been identified.

${ }^{14}$ SSRI discontinuation included somatic symptoms such as dizziness, lethargy, and sleep disturbances, as well as psychological symptoms such as anxiety/agitation, irritability, and poor concentration. The literature provides very limited information on possible mechanisms.

${ }^{15}$ It has been proposed that an SSRI-induced increase in gastric acid secretion may explain the gastrointestinal bleeding risk and that SSRI-related effects on platelet reactivity, endothelial reactivity, and inflammatory markers may explain the protective effect against ischemic heart disease.

${ }^{16} \mathrm{~A}$ comprehensive literature review indicated that citalopram (8 cases), fluoxetine (6 cases) and sertraline ( 1 case) can rarely be associated with torsades de pointes. There is general agreement in the literature that most drugs that cause torsades de pointes can be identified by assessing whether 
they block the human ether à gogo related gene (hERG) potassium channel and prolong the QT interval on the electrocardiogram, but it is not well understood why some drugs that block this channel do not cause torsades de pointes. Johannesen et al. [144] have proposed that drugs at the same concentration level that block the inward calcium or sodium channels also offset the protorsade effect of blocking the outward hERG potassium channels.

${ }^{17}$ Brugada syndrome is described in footnote 7 of Figure 3.

${ }^{18}$ All antidepressants are probably able to cause hyponatremia on rare occasions. It usually happens in geriatric patients, particularly females. The literature usually describes these cases as SIADH but it is not clear why antidepressants can cause SIADH.

5-HT: Serotonin receptor; ADR: Adverse drug reaction; common: ADR $\geq 10 \%$ in RCT; ECG: Electrocardiogram; H: Histamine receptor; M: Muscarinic receptor; TCA: Tricyclic antidepressant; RCT: Randomized clinical trial; SIADH: Syndrome of inappropriate antidiuretic hormone; SNRI: Serotonin and noradrenaline reuptake inhibitor; SSRI: Selective serotonin reuptake inhibitor. 